Universidad de Lima

Facultad de Psicología

Carrera de Psicología

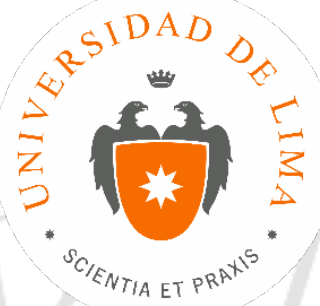

PROPIEDADES PSICOMÉTRICAS DEL

ORGANIZATIONAL CULTURE

ASSESSMENT INSTRUMENT (OCAI) EN

COLABORADORES DE LIMA

METROPOLITANA

Tesis para optar el título profesional de Licenciado en Psicología

$$
\text { Jimena Cerpa Noya }
$$

20090221

Asesor

Mónica Fernández Otoya

Lima - Perú

Febrero del 2018 


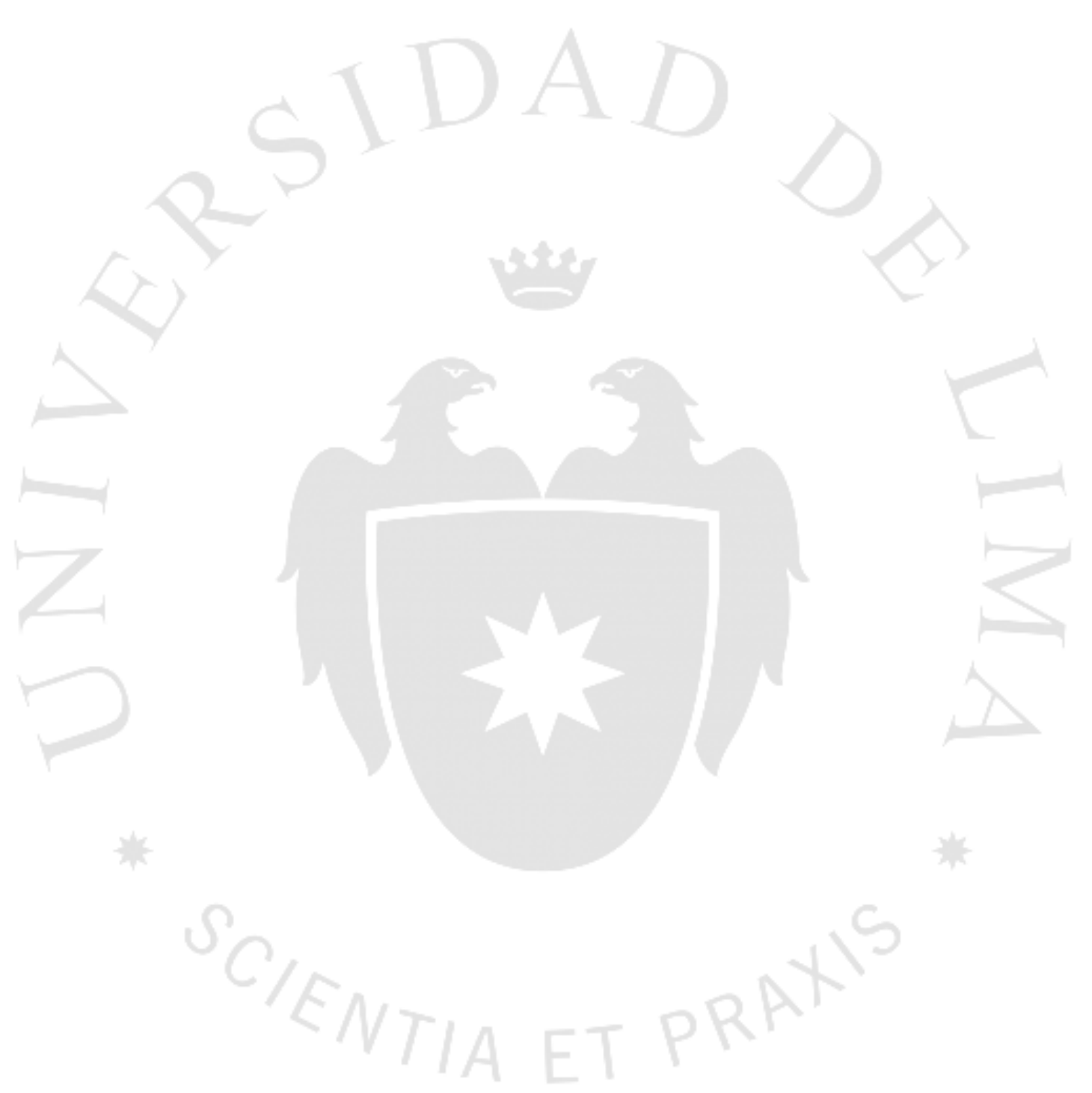




\section{PROPIEDADES PSICOMÉTRICAS DEL}

$$
\text { ORGANIZATIONAL CULTURE }
$$

ASSESSMENT INSTRUMENT (OCAI) EN

COLABORADORES DE LIMA

METROPOLITANA 


\section{TABLA DE CONTENIDO}

CAPÍTULO I: PLANTEAMIENTO DEL PROBLEMA...........................2

1.1 Descripción del problema..........................................2

1.2 Justificación y relevancia........................................4

CAPÍTULO II: MARCO TEÓRICO.............................................6

2.1 Definición de Cultura Organizacional..............................6

2.1.2 Funciones de la Cultura Organizacional............................8

2.1.3 Iceberg de la Cultura Organizacional..............................9

2.2 Modelos teóricos de la Cultura Organizacional.........................10

2.2.1 Modelo de Denison...................................................11

2.2.2 Modelo de MVC.................................................. 12

2.3 Evidencias empíricas acerca del OCAI y su relación con otras variables..17

CAPÍTULO III: OBJETIVOS Y DEFINICIÓN DE VARIABLES.

3.1 Objetivos................................................... 19

3.1 .1 Objetivo general........................................... 19

3.1.2 Objetivos específicos........................................ 19

3.2 Definición de variables............................................... 19

3.2.1 Definición conceptual de Cultura Organizacional.....................19

3.2.2 Definición operacional de Cultura Organizacional.....................20

CAPÍTULO IV: MÉTODO......................................................21

4.1 Tipo y diseño de investigación..................................21

4.2 Participantes....................................................... 21

4.3 Técnicas de recolección de la información...........................23

4.4 Procedimiento de recolección de datos...............................26

CAPÍTULO V: RESULTADOS................................................28

5.1 Análisis psicométrico......................................28

5.2 Evidencias de validez vinculadas al contenido......................28 
5.3 Evidencias de validez vinculadas a la estructura interna.................30

5.4 Análisis de la discriminación de los ítems del OCAI....................33

5.5 Estimación de la confiabilidad de las puntuaciones derivadas de la aplicación de los ítems que conforman el OCAI .34

5.6 Análisis descriptivo de las puntuaciones obtenidas del OCAI.... 35

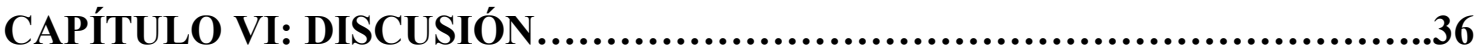

6.1 Análisis de las propiedades psicométricas del OCAI....................36

6.2 Estándares para la Evaluación Educativa y Psicológica........................38

6.2.1 Estándares para la validez......................................38

6.2.2 Estándares para la confiabilidad....................................40

6.2.3 Estándares para la administración, puntuación e interpretación...........41

6.3 Interpretación de las puntuaciones del OCAI en función a investigaciones anteriores .41

CONCLUSIONES .................................................................46

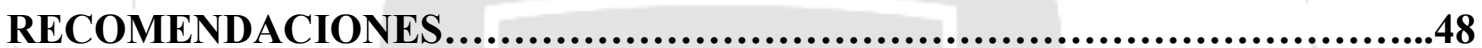

REFERENCIAS...............................................................50 


\section{ÍNDICE DE TABLAS}

Tabla 4.1 Distribución de la muestra según variables sociodemográficas

Tabla 5.1 Evidencias de validez vinculadas al contenido del OCAI 30

Tabla 5.2 Análisis factorial exploratorio de los ítems del OCAI con dos factores rotados de forma oblicua. 32

Tabla 5.3 Análisis de la discriminación ítem total del Factor 1. .33

Tabla 5.4 Análisis de la discriminación ítem total del Factor 2..... 34

Tabla 5.5 Alfa de Cronbach, Alfa Ordinal y Error Estándar de Medición para las puntuaciones derivadas de los ítems del OCAI. .35

Tabla 5.6 Estadísticos descriptivos de las puntuaciones obtenidas correspondientes a la aplicación del OCAI..........................................................

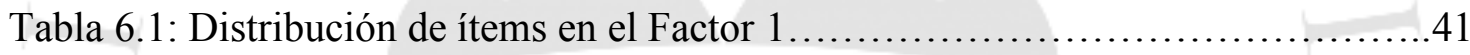

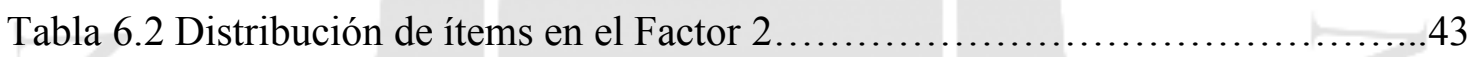




\section{ÍNDICE DE FIGURAS}

Figura 2.1 Modelo de Valores de Competencia..................................... 14 


\section{ÍNDICE DE ANEXOS}

Anexo 1: Matriz Organizativa del OCAI.....................................60

Anexo 2: Organizational Culture Assessment Instrument propuesta inicial..........61

Anexo 3: Organizational Culture Assessment Instrument propuesta final.............65

Anexo 4: Criterio de Jueces: Carta de Presentación................................68

Anexo 5: Formato para validar instrumento con juicio de expertos.................70

Anexo 6: Consentimiento Informado ........................................ 75 


\section{INTRODUCCIÓN}

El trabajo de investigación tiene como objetivo analizar y determinar las propiedades psicométricas del instrumento Organizational Culture Assesment Instrument (OCAI) en una muestra de 211 colaboradores que laboran en empresas de sectores públicos y privados en Lima Metropolitana. Adicionalmente, se describirán los resultados según criterios de: edad, género, tiempo de permanencia en la empresa, área y rubro.

El instrumento en mención tiene como base teórica el Modelo de Valores en Competencia de Cameron y Quinn (1999), este modelo explica cuatro tipos de cultura: Clan, Adhocrática, Burocrática y de Mercado cada una agrupada en un cuadrante.

Los resultados obtenidos en el análisis psicométrico muestran que el instrumento utilizado posee altos niveles de confiabilidad y evidencias validez interna, sin embargo, no se logró replicar la estructura teórica del instrumento original debido a que los ítems seleccionados por los participantes no permitieron discriminar entre los cuatro tipos de cultura, sino solo dos.

A continuación, se desarrolla el planteamiento del problema que motivó la presente investigación, su justificación y limitaciones. Luego, se establece el marco teórico, se brinda antecedentes sobre investigaciones nacionales e internacionales acerca de la cultura organizacional y su impacto en las organizaciones. Por último, se explicará el instrumento, muestra y alcance de la investigación y los resultados expuestos.

Palabras clave: Cultura organizacional, percepción, OCAI, Modelo de Valores en Competencia. 


\section{CAPÍTULO I: PLANTEAMIENTO DEL PROBLEMA}

\subsection{Descripción del problema}

Según Schein (1985), la cultura organizacional es el conjunto de creencias y códigos que un grupo de personas aprende a medida que va solucionando un problema y que caracterizan su comportamiento en el tiempo. La cultura de una empresa entonces, se puede observar a través de las manifestaciones comportamentales de sus miembros: los estilos de liderazgo, sus decisiones, la forma en que se relaciona con sus colaboradores y la sociedad, etc.

La cultura organizacional es objeto de exploración en el mundo de la Gestión Humana y Empresarial debido a la necesidad de transformación que experimentan las organizaciones producto de los cambios del entorno en el que operan. Las organizaciones, por ende, buscan construir culturas organizacionales flexibles y con capacidad de adaptación para competir y sobrevivir.

De acuerdo con Van (2012), uno de los temas más retadores para el 60\% de las compañías de Latinoamérica es el de su cultura organizacional. En una investigación de la Consultora Deloitte en el entorno peruano, se muestra que el 50\% de ejecutivos cita la problemática de cultura organizacional y falta de compromiso como "muy importante" en su agenda empresarial, además, se menciona que solo el 12\% de las empresas afirma haber establecido un programa para definir y fortalecer su cultura corporativa.

Robbins y Judge (2013), sostienen que en todas las empresas los trabajadores pueden observar lo mismo, pero la interpretación de lo que observan es diferente en cada uno; a partir de ello se puede observar la cultura que ellos perciben en su propia empresa, la cual tiene como trasfondo una serie de creencias y los valores que nos permiten entender "cómo se hacen las cosas en la compañía". De allí que es importante entender cómo es la cultura de una organización o cuáles son los patrones de comportamiento que comparten los miembros de la organización porque estos pueden estar favoreciendo o no el logro de los resultados de la compañía. La cultura organizacional es un factor clave para el negocio, ya que al gestionarla puede optimizar sus resultados y hacerla sostenible en el tiempo.

De acuerdo con Castillo (2012), Gerente General de Psigma Corp., en el Perú, hace unos años no había claridad y comprensión sobre las implicancias que tiene la 
cultura corporativa en los negocios, sin embargo, hoy en día muchas empresas están gestionándola, aunque el tema todavía es ajeno para la mayoría. La cultura organizacional en nuestro país es una realidad desatendida, desde la definición, la constante falta de diferenciación entre clima y cultura, el impacto de la cultura en la estrategia del negocio, entre otros.

Debido a la necesidad de contribuir con la optimización de resultados de las empresas y su sostenibilidad en el tiempo es que nace la necesidad de explorar el concepto de cultura y adaptar un instrumento que permita observarla, medirla y controlarla de manera válida y confiable. Actualmente, en nuestro país no contamos con instrumentos adaptados a nuestra realidad para lograr este objetivo.

Frente a esta necesidad, se presenta el OCAI, como un instrumento creado por Cameron y Quinn (1999) que permite identificar 4 tipos de cultura que pueden caracterizar a una empresa (Clan, Adhocrática, Burocrática y de Mercado), y que brinda información sobre el tipo de cultura a la que aspira la empresa, con el objetivo de identificar las brechas entre la cultura actual y la cultura deseada. Adicionalmente, está respaldado por su modelo teórico, el Modelo de Valores de Competencia, el cual ha sido utilizado para la medición y comprensión de la cultura organizacional en varios países a nivel mundial. Esta herramienta de medición es bastante utilizada y respetada académicamente (Helfirch, Yu-fang, Mohr, Meterko y Sales, 2007); sin embargo, a pesar de su uso extendido es indispensable validar sus propiedades psicométricas en cada estudio (Hartnell, Ou y Kinicki, 2011).

Para adaptar y validar el cuestionario OCAI en Lima Metropolitana, analizando sus propiedades psicométricas, es necesario realizar un estudio en trabajadores de diferentes rubros de empresas. Es por eso que la pregunta de investigación es: ¿Cuáles son las propiedades psicométricas del Organizational Culture Assesment Instrument? Para mayor detalle se disgrega en preguntas específicas como: ¿Cuáles son las evidencias de validez vinculadas al contenido? ¿Cuáles son las evidencias de validez vinculadas a la estructura interna? ¿Cuáles son las evidencias de confiabilidad de las puntuaciones derivadas? ¿Cuál es la capacidad discriminativa de los ítems? 


\subsection{Justificación}

A nivel práctico, la presente investigación pretende poner al alcance de las empresas y en especial a los profesionales de gestión humana, un instrumento adaptado a la población de Lima Metropolitana para contribuir con el diagnóstico de su cultura actual. Realizar un diagnóstico cultural periódico, le permitirá a la empresa conocer sus patrones comportamentales en un momento dado a fin de intervenir en ella con mayor probabilidad de éxito, para generar los cambios que se consideren necesarios, en favor de la consecución de los objetivos estratégicos de la organización. Hernández, Méndez y Contreras (2014), sostienen que no existe una herramienta perfecta para medir cultura organizacional, sin embargo, de abordar el estudio de la cultura de una compañía, se deben utilizar herramientas que levanten información tanto cuantitativa, como cualitativa. De allí que se está proponiendo la herramienta OCAI para el levantamiento de información cuantitativo respectivo. La importancia de contar con un instrumento de medición estandarizado yace en la necesidad de garantizar la validez y confiabilidad de herramientas con técnicas psicométricas y solidez en el método científico. La objetividad con que se interpreten los resultados hace foco en eliminar y reducir sesgos propios del evaluador y de la población, dependencia del contexto cultural, uso ético, lenguaje, entre otros (Hernández, Fernández y Baptista, 2014)

Adicionalmente, a nivel práctico en el campo de la investigación, el contar con un instrumento estandarizado en Lima, para medir cultura organizacional en las organizaciones, permitirá ahondar en el estudio del éxito organizacional a partir de la comprensión de los patrones comportamentales de culturas exitosas en diferentes sectores, giros de negocio, espacio geográfico, etc. Adicionalmente, más adelante se describirá cómo la cultura viene siendo relacionada con estilos de liderazgo, desempeño, clima y bienestar general en la empresa.

A nivel teórico, la información obtenida busca fortalecer el Modelo de Valores en Competencia de Cameron y Quinn, autores del cuestionario. Modelo que por su solvencia, simplicidad y fácil entendimiento viene siendo el preferido por los diferentes profesionales que estudian la cultura de las organizaciones a nivel mundial. En caso de no lograr la estandarización, es relevante contar con elementos objetivos que permitan enriquecer dicho modelo o cuestionar algunos de sus fundamentos.

A nivel metodológico, la presente investigación permitirá identificar las fortalezas del cuestionario OCAI dentro de una batería de herramientas utilizadas para el abordaje 
diagnóstico de cultura organizacional. A partir de los resultados obtenidos pretendemos hacer un planteamiento con cierto nivel de peso en los datos obtenidos en el levantamiento cuantitativo, versus el cualitativo. 


\section{CAPÍTULO II: MARCO TEÓRICO}

\subsection{Definición de Cultura Organizacional}

Schein (1985), autor muy mencionado y gran referente de este constructo, sostiene que la cultura organizacional es un patrón básico de creencias y códigos que un grupo aprende a medida que va solucionando un problema. De esta manera se va adaptando a los cambios con el fin de mantener la cohesión interna entre los propios miembros. Es así como esta interacción de creencias de soluciones exitosas pasa de generación en generación.

Según Aguirre (2002), la cultura organizacional se define como un conjunto de elementos interactivos fundamentales, generales y compartidos por la organización como eficaces para alcanzar sus objetivos, que cohesionan e identifican, por lo que deben ser transferidos a los nuevos miembros.

Schein (1988) afirma que debido a las experiencias compartidas que obtienen un grupo de personas para la solución de problemas externos e internos, ha traído como resultado que los miembros perciban estas prácticas como una visión del mundo que los rodea y el lugar que ocupan en él. Por ello, cada grupo es una cultura y cada grupo se consolida a la vez que construye su cultura (Aguirre, 2002). De lo expresado anteriormente se puede desprender que toda organización tiene una cultura y se va creando en función a la propia interacción entre sus colaboradores.

La estrategia de la organización puede estar basada en alinear las creencias y valores de sus trabajadores junto con los de la compañía, de esta forma, la cultura puede ser vista como un recurso o un medio para llegar a un fin que si se agrega valor puede llegar a convertirse en ventaja competitiva que los lleve al éxito (Barney, 1986).

En una organización, el inicio de la cultura se debe en gran parte a la participación de los fundadores como fuente primaria. Ellos tienen una visión de lo que la organización debería ser o quiere llegar a ser, por lo cual, la cultura se va creando con el enfoque estratégico de estos líderes quienes tratarán de insertar personas que piensen y sienten como los que están dentro y así agilizar el proceso de incorporación cultural. Es así como la conducta de los mismos fundadores anima a los nuevos miembros a identificarse con la organización y a internalizar y formar conciencia de sus valores, creencias y suposiciones. Aguirre (2002) complementa indicando que la cultura de una empresa 
surge desde dentro de la organización, debido a los esfuerzos de sus líderes y miembros por resolver sus problemas en favor de alcanzar un objetivo común de grupo.

El desarrollo de la cultura se presenta en cualquier comunidad de individuos que interactúan y se relacionan al percibir objetivos, intereses, creencias, valores, rutinas y necesidades que comparten entre ellos (Rodríguez, 2009). Maldonado, Martínez y García (2010), sostienen que la forma de trabajar y de relacionarse al interior de la empresa está determinada por una buena coordinación y organización en la cual existe cohesión en las reglas y políticas claras para mantener la estabilidad y el control en la organización.

La importancia de la cultura en las organizaciones juega un papel tan importante en esta que se han realizado muchos estudios para encontrar la manera de que sean más productivas, competitivas y rentables (Morales, Hernández y Medina, 2009, p. 50).

De las cientos de empresas fundadas desde el año 1900 al 2006, solo dieciséis de ellas siguen en pie. La estrategia de sobrevivencia organizacional ha cambiado drásticamente considerando el cambio que hubo en el proceso de transformación de la era industrial a la era de la información. La mayoría no se atreve a predecir los cambios que se vienen suscitando, pero lo que todos aseveran es que la velocidad con lo que los cambios están ocurriendo seguirán creciendo exponencialmente (Cameron, 2003; Quinn, 2000). Estos cambios rápidos retan la capacidad competitiva y de supervivencia de una organización. El reto ahora para muchas empresas es facilitar el cambio para incrementar la eficacia y eficiencia de la organización producto de su capacidad de aprendizaje, adaptación y rapidez de respuesta frente al entorno.

Aunque la cultura organizacional se ha convertido en un concepto popular para los investigadores en el análisis de los fenómenos organizacionales, una revisión de la literatura según Delobbe, Haccoun, y Vandenberghe (2000) indica que entender la cultura organizacional es una de las mejores herramientas que se necesitan para medir la efectividad organizacional. De manera similar, Sánchez (2008), asegura que no hay una definición comúnmente aceptada de cultura ya que puede ser interpretada desde diferentes áreas (psicológica, sociológica, organizacional, etc.). Para efectos de esta investigación se utilizará la definición, el modelo y el instrumento propuesto por Kim Cameron y Robert Quinn (2006) ya que se considera la más completa y de fácil entendimiento.

De acuerdo con lo señalado, entender la cultura organizacional, darle la atención debida y administrarla, empoderará a los líderes para maximizar el capital intelectual, actitudinal y conductual de su gente (Darcey-Lymn y Farbrother, 2003). Sin identidad 
cultural, el grupo no sabe si "es", por lo tanto, su existencia no puede consolidarse (Aguirre, 2002).

\subsubsection{Funciones de la Cultura Organizacional}

De acuerdo con Díez y Dominguez (1996), las principales funciones de la cultura en una organización son:

- Función socializadora: El individuo es una persona social, con quien comparte su forma de pensar y actuar con otros miembros de la misma organización. De esta manera, los grupos de personas que viven en condiciones similares logran desarrollar soluciones comunes (Clay, 1978).

- Función identificadora: Desde el punto de vista de Goffman (1972), esta es la principal función de la cultura en la organización, ya que se tiene en cuenta la cohesión interna del grupo, la creación de una realidad compartida y se genera identidad en cuanto el individuo se convierte en partícipe en una entidad social la cual implica compromiso y adhesión afectiva.

- Función integradora: El individuo no solo se siente integrado al grupo al que pertenece, sino que siente el permiso para marginar a los que no formen parte de este (Bolívar, 1993).

- Función adaptativa: Según Schein (1988), la cultura se debe encargar de dar solución a los miembros de la organización sobre la supervivencia y adaptación del método que los rodea, así como la integración de sus procesos internos con el fin de consolidar la capacidad de supervivencia y adaptación.

- Función instrumental: Se refiere al uso de la cultura como medio para conseguir objetivos organizacionales y para potenciar cambios sociales (Infestas, 1991)

- Función reguladora: Es como el contrato social interno que ayuda a regular el comportamiento de los miembros de la organización. Es importante considerar que a través del control ejercido se podrá predecir la conducta de los miembros (Robbins, 1987).

- Función motivadora: Los valores compartidos motivan al personal (Kast y Rosenzweig, 1987) y facilita el compromiso con el grupo (Robbins, 1987). 


\subsubsection{Iceberg de la Cultura:}

Schein (1988) distingue tres niveles de observación para recabar información sobre la cultura de una organización, los cuáles no son estáticos ni independientes, sino se interrelacionan y conforman las creencias y las presunciones básicas de la cultura organizacional:

a. Nivel 1 (Artefactos): Es el nivel más visible. Es el entorno físico y social, caracterizado por las manifestaciones visibles, audibles y perceptibles de las suposiciones subyacentes como rituales, pautas de comportamiento, entorno físico, ropa, historias, mitos y productos.

b. Nivel 2 (Valores compartidos): Son las razones explícitas que justifican que las cosas son como son; por ejemplo: estatutos, metas, normas, códigos éticos, declaración de principios.

c. Nivel 3 (Suposiciones Subyacentes): Es el nivel menos visible. Son los motivos implícitos que explican por qué los miembros del grupo perciben, piensan y sienten en la forma en que lo hacen frente a los problemas externos e internos como la misión, los medios, las relaciones, la realidad y el tiempo.

Los supuestos fundamentales son compartidos por los mismos miembros y a su vez son reforzados mutuamente. Una vez interiorizados las suposiciones subyacentes, el trabajador va a poder identificar y darles un mayor sentido a los dos primeros niveles.

Por otro lado, la descripción de algunos de los elementos de la cultura organizacional según Aguirre (2004) son:

- Etnohistoria: Aquí se narran los orígenes, el pasado, el presente y los proyectos a futuro. La historia va a proporcionar la identidad no solo del grupo, sino de la organización, desde dónde somos, quiénes somos y a dónde vamos (Serra, 2004).

- Etnoterritorio: Se hace mención al espacio físico que da lugar al nacimiento de esta cultura organizacional (edificios, áreas de producción, etc.).

- Creencias: Se configuran a través de esquemas (representaciones mentales del mundo) y fundamentan el comportamiento ideal y colectivo.

- Mitos: Es una narración carente de orientación y sentido, asociados a acciones o personajes que sirven para ejemplificar el comportamiento de los integrantes de la organización (Aguirre, 2000).

- Religión: Sistema ritual de participación: rituales de entrada, poder, fiesta de despedida y se presentan elementos como: escudo, logo bandera, etc. 
- Valores: conjunto de creencias que la organización tiene sobre determinadas conductas específicas y sobre los fines u objetivos de su existencia. Son los principios que deben ser cumplidos en la organización. Surge de la historia organizacional, las decisiones de sus miembros, las acciones cotidianas y el día a día.

- Los lenguajes: Robbins y Judge (2013) la describen como los términos únicos para describir el equipo, los funcionarios, proveedores, clientes o productos que se relacionan con el negocio. Entre los lenguajes de la empresa, se pueden distinguir entre lenguajes internos (jergas, vestimenta, lenguaje jerárquico, etc) y lenguaje externo (recepción de clientes, publicidad, ventas, logotipos y demás símbolos de identidad, etc).

- Rituales: Son una serie de actos formalizados y estereotipados por la organización. Por ejemplo, el comportamiento de los gerentes en reuniones, selección del equipo colaborador, comportamiento de los empleados, atención al cliente, entre otros.

\subsection{Modelos de la Cultura Organizacional}

Se han planteado modelos culturales con el objetivo de hallar tipologías culturales que permitan agrupar patrones comportamentales propios de sus miembros. De acuerdo con Cantú (2001), la cultura organizacional puede observar a través de patrones comportamentales generales referidos a:

- Identidad de sus miembros: El grado en que los colaboradores se identifican con la organización.

- Énfasis de grupo: Las actividades laborales son grupales y no individuales.

- Enfoque hacia las personas: Las decisiones administrativas toman en cuenta la repercusión de los resultados que tendrá en los miembros de la organización.

- El control: Uso de reglamentos, políticas y procesos para controlar la conducta de los miembros.

- Tolerancia al riesgo: Es el grado en que se fomenta que los empleados sean agresivos, innovadores. 


\subsubsection{Modelo de Denison}

El modelo de Denison vincula la cultura oganizacional con el rendimiento principal del crecimiento de las ventas, rentabilidad sobre recursos propios (ROE), retorno de la inversión (ROI), la satisfacción del cliente, innovación, satisfacción del empleado, entre otros. Denison (1996) define la cultura como una estructura profunda de la organización, enraizada en los valores, creencias y supuestos de la base de sus miembros.

La investigación de este autor se diferencia de otros estudios ya que se basa en cómo influye la cultura en el desempeño organizacional y se centra en los rasgos culturales. Este modelo se basa en cuatro características culturales o dimensiones que expresan creencias y supuestos que influyen en la conducta y que determinan la cultura organizacional. Cada una de estas características se mide a través de tres índices y cada uno de ellos se mide a través de cinco ítems.

Según Denison (1991), existen 4 dimensiones en la cultura organizacional:

- Implicación: se refiere a que las organizaciones se organizan en equipos y desarrollan competencias. Es importante que estos se sientan parte de la empresa y se comprometan con esta. En las organizaciones efectivas se caracteriza por delegar y dar poder a la gente, además de organizarse mediante equipos y reconocer la capacidad humana en todos los niveles de la organización para participar en la toma de decisiones. Responde a la pregunta: ¿Nuestra gente está alineada, comprometida y con capacidad? Dentro de esta dimensión se encuentran las subescalas: Empoderamiento, trabajo en equipo y desarrollo de capacidades.

- Consistencia: Las organizaciones son efectivas cuando son coordinadas y bien integradas. La conducta de las personas está marcada por los valores que inducen a los líderes y seguidores a llegar a un acuerdo común. La consistencia es vista como fuente de estabilidad e integración interna resultado de una visión compartida y alto grado de conformidad. Responde a la pregunta: ¿Tenemos valores, sistemas y procesos para ejecutar? Se mide a través de los siguientes índices: Valores centrales, acuerdo y coordinación e integración.

- Adaptabilidad: El cambio al nuevo entorno lleno de retos y desafíos es imprescindible. Las organizaciones adaptativas aprenden de sus errores, siempre ven oportunidades, y viven de la experiencia para introducir cambios. Se mide por las subescalas: orientación al cambio, orientación al cliente y aprendizaje organizativo. 
- Misión: Las organizaciones deben saber a dónde se dirigen, deben contar con un propósito y una dirección, es por eso que responde a la pregunta: ¿Sabemos a dónde nos dirigimos? Es la que define una dirección significativa de largo plazo en la organización. Los índices que componen esta dimensión son: dirección y propósitos estratégicos, metas y objetivos y visión.

Las investigaciones de Denison han demostrado que las organizaciones efectivas tienen altos niveles en sus cuatro dimensiones (Denison, Janovics, Young, Cho, 2006).

Por último, las orientaciones de la cultura organizacional según el marco teórico que se pueden encontrar son:

- Enfoque externo (Adaptabilidad + Misión): La organización con un fuerte enfoque externo se orienta en la adaptación y cambio que el medio ambiente demande. También está enfocado en el mercado organizacional y adonde este se dirige. Un enfoque externo impacta en los ingresos, crecimiento de las ventas, cuota de mercado.

- Enfoque interno (Implicación + Consistencia): Se basa en la dinámica de integración de los procesos, estructuras y sistemas. Está relacionada con altos niveles de calidad, menos defectos, menos re trabajo, buena utilización de recursos y alta satisfacción laboral.

- Flexibilidad (Adaptabilidad + Implicación): Una organización flexible está vinculada con altos niveles de producción, innovación, creatividad y atendiendo rápidamente a las necesidades del cliente.

- Estabilidad (Misión + Consistencia): Una organización estable tiene la capacidad de mantenerse enfocada y ser predecible en el tiempo.

\subsubsection{Modelo de Valores en Competencia (MVC)}

El instrumento de evaluación de cultura organizacional utilizado en el presente estudio se basa en el Modelo de Valores en Competencia (MVC) y surge como resultado de determinar los indicadores de eficacia en una organización. Es así como Quinn y Rohrbaugh (1983) analizaron una lista de 39 indicadores para determinar e identificar estos patrones. Dado que treinta y nueve es un gran número, los indicadores pasaron por un análisis estadístico del cual surgieron 2 grandes dimensiones que se organizaron en 4 grupos principales, es decir, los cuatro tipos de cultura. 
La primera dimensión diferencia los criterios de eficacia, que hacen énfasis en la flexibilidad, la discreción y el dinamismo de los criterios que hacen hincapié en la estabilidad, el orden y el control. A partir de ello se determina que el criterio para definir la eficacia de una organización está sujeta a distintos indicadores de medición. Por ejemplo, algunas organizaciones son vistas como eficaces si son cambiantes y adaptables, sin embargo, también hay otro tipo de compañías que son percibidas como eficaces si son estables, predecibles y operativas.

La segunda dimensión se diferencia del criterio de efectividad, el cual enfatiza la orientación interna, integración y unidad, del criterio que enfatiza la orientación externa y la diferenciación. Es el caso de las organizaciones que son vistas como efectivas si tienen características internas equilibradas.

Ambas dimensiones producen cuadrantes, el primero de ellos, que se encuentra en el cuadrante superior de izquierda, identifica valores que enfatiza el aspecto interior de una organización, mientras que el cuadrante derecho inferior enfatiza en lo externo. Los cuadrantes son: Clan, Adhocracia, Jerárquica y de Mercado. En la Figura 2.1 se puede observar las dos dimensiones representadas por los ejes y los tipos de cultura según el cuadrante donde pertenecen.

El objetivo de utilizar este modelo es diagnosticar y facilitar el cambio de la cultura organizacional en las organizaciones. Este método está probado empíricamente y tiene validez (Cameron y Ettington, 1988; Quinn, 1988). El MVC ofrece esquemas categóricos que organizan la forma de pensar, valores, supuestos y la forma en que los colaboradores procesan la información. 


\section{MODELO DE VALORES DE COMPETENCIA}

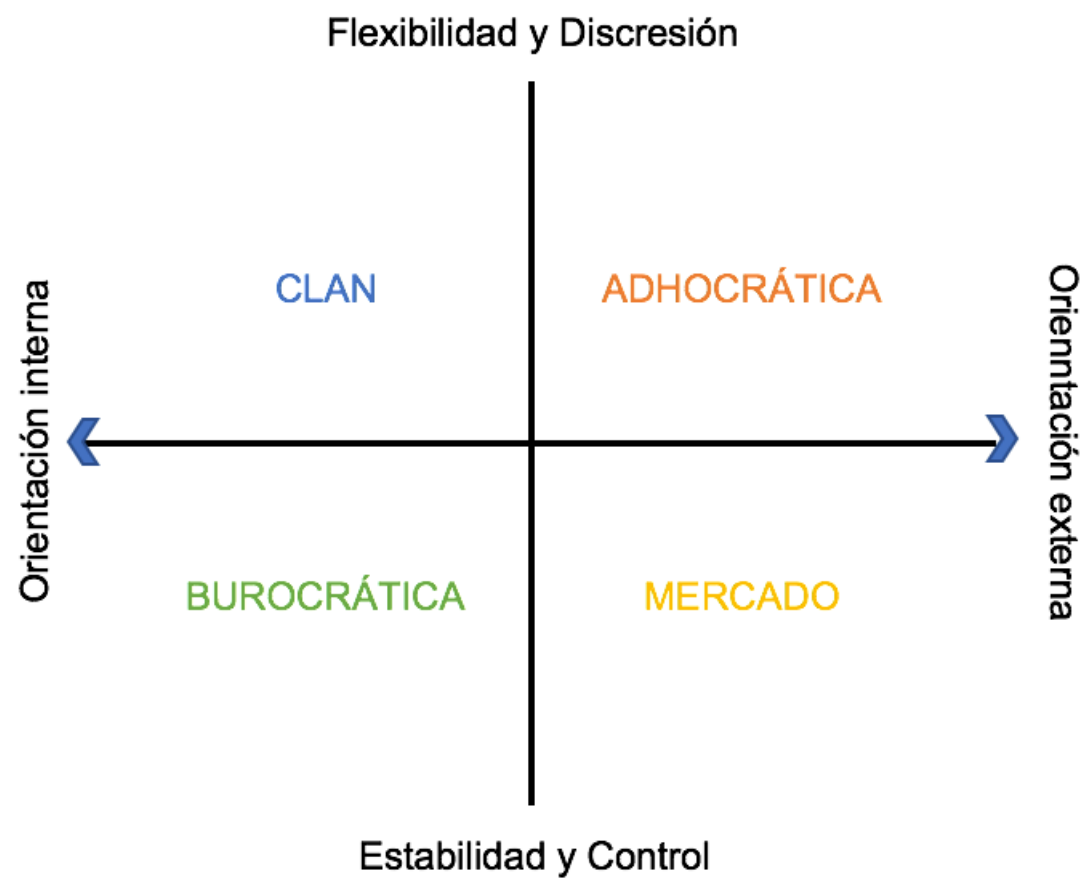

Figura 2.1

Modelo de Valores en Competencia

Considerando el modelo teórico de Cameron y Quinn (1999) y el que se está tomando como base para este estudio, se ha tomado en cuenta la tipología descrita por los autores:

- Clan: Se llama clan por su similitud con una organización de tipo familiar, Este tipo de organizaciones se caracterizan por ser lugares amigables para trabajar, generar sentido de familia y los líderes son vistos como mentores porque fomentan la lealtad, la tradición, la cohesión y la participación entre los miembros, es por eso que el compromiso es alto y hay desarrollo individual. Los miembros comparten las creencias y los valores. Una de las suposiciones principales de la cultura clan es que el ambiente puede ser manejado a través del trabajo en equipo y desarrollo del colaborador. Los miembros de este tipo de organizaciones tienden a compartir los mismos valores, creencias y metas y así logran ser más efectivos. Asimismo, presentan un alto nivel de compromiso y se distinguen por ser leales y tradicionales. 
- Emprendedora: La suposición principal de este tipo de cultura es que la innovación y la iniciativa llevan al éxito; el principal negocio de las organizaciones es desarrollar nuevos productos y servicios para el futuro y así adaptarse rápidamente a las nuevas oportunidades. La tarea más grande es fomentar la creatividad y el emprendimiento, así como también la adaptabilidad y la flexibilidad en los colaboradores. Entonces, en este eje se encontrará un tipo de cultura caracterizado por ser un lugar de trabajo dinámico, emprendedor y creativo donde los colaboradores asumen riesgos. Los líderes son personas visionarios, innovadores y orientados al riesgo. Lo que une a la organización es el compromiso para explorar e innovar.

- Jerarquía: Tiene como referencia una base socialista, inspirada en los trabajos de Max Weber quien estudió el gobierno de las organizaciones con el fin de ser hallar la manera de ser más eficientes en productos y servicios para una sociedad compleja. Estas 7 características de Weber (1947) que se convirtieron en los atributos clásicos de la burocracia eran: Reglas, especialización, meritocracia, jerarquía, bienes separados, impersonalidad y responsabilidad. Estos atributos eran tan efectivos que hasta los años 60's en los libros de administración de empresas la suposición de Weber era la forma ideal de formar una organización. Siguiendo con la misma línea, este tipo de cultura está caracterizado por ser un lugar formal y estructurado de trabajo en donde los procedimientos gobiernan la conducta de los colaboradores y de esta manera las políticas y las reglas mantienen a la organización. Los líderes efectivos son buenos coordinadores y organizadores. La preocupación a largo plazo es la estabilidad, predictibilidad y eficiencia, por ello, la cultura está normada en cuanto a funciones, responsabilidades, procesos, procedimientos, tareas, etc. En este caso los nuevos empleados en un inicio solo hacen un trabajo en específico, tienen trabajos especializados.

- Mercado: Otra forma de organización nace a finales de los años 60's en donde las compañías se enfrentaban a nuevos retos. Este tipo de cultura está orientado al ambiente externo, constituido principalmente por los clientes, los contratistas, las licencias y reguladores. El foco del mercado es conducir distintas transacciones con otros para crear ventajas competitivas y así llevar a la organización a ser más productiva y a alcanzar los resultados deseados. Es por ello que el lugar de trabajo está orientado al resultado tal que busca un perfil de líderes productivos, competitivos y demandantes. A largo plazo la 
preocupación está ligada a acciones competitivas, metas y blancos. Los principales valores que dominan este tipo de cultura son la competitividad y la productividad.

La cultura organizacional tiene características vinculadas con los miembros de una organización: No puede existir independientemente de los miembros quienes la crearon ya que esta es producto de las acciones de tales miembros (Trice y Breyer, 1993). Otra característica es que es dinámica, esto sucede porque hay un sinfín de mensajes verbales y no verbales que pueden ser enviadas como recibidas (Bantz, 1993).

Asimismo, no es estática, está en permanente transformación y es vista como el resultado de interrelaciones individuales y colectivas, simples y complejas; es el proceso vital en el que se encuentra el sentido de orientación, la forma específica de ser y de pertenencia a un grupo social, encontrando así el sentido de la cohesión social (Zaragoza, 2010).

La mayoría de las organizaciones tienen una cultura dominante la cual va a expresar los valores fundamentales que comparte la mayoría de sus miembros. Dentro de ella se pueden formar subculturas las cuales tienden a desarrollarse en organizaciones grandes para reflejar problemas o experiencias comunes que hay en una misma área (Hoffman y Jones, 2005). Las subculturas son aquellas subunidades culturales que carecen de autonomía para existir como independientes y que anidan dentro de las culturas organizacionales.

\subsection{Evidencias empíricas acerca de la efectividad del OCAI y su relación con otras} variables

Con respecto a la cultura organizacional y los estudios realizados con relación a otras variables como los valores organizacionales, se encuentra la investigación hecha por Espaillat (2012), la cual tuvo como finalidad identificar la cultura y valores organizacionales en trabajadores a nivel operativo de una empresa y evaluar la relación existente entre estas dos variables. Se llega a la conclusión de que sí hay una relación entre cultura organizacional y valores organizacionales. Se menciona que, mientras más comprometidos estén los trabajadores con los valores, la cultura tiene más fuerza.

En esta otra investigación de la misma línea, llevada a cabo por Calderón Hernández (2003), se busca establecer la relación entre bienestar laboral y cultura organizacional. Los resultados muestran que la satisfacción del trabajador está asociada con culturas orientadas al empleado, corporativistas, abiertas, pragmáticas. 
Adicionalmente, Lynn, 1988; Ogbonna y Harris, 2002 y Yeung, Brockbank y Ulrich, 1991; han establecido relaciones entre los recursos humanos y la cultura organizacional. Según Berg (1986), la gerencia de los recursos humanos se constituye en el marco estratégico de la cultura organizacional. Cuando la organización quiere mantener una cultura fuerte necesita enfocarse en las políticas de recursos humanos y asegurarse que estas apoyen a la cultura deseada (Ogbonna y Whipp, 1999).

Otra investigación que resalta la relación entre Recursos Humanos y la cultura organizacional, se llevó a cabo por Calderón y Serna (2009) el cual tuvo como objetivo identificar la relación entre ambas variables. El contraste empírico se llevó a cabo en grandes empresas industriales colombianas a cuyos jefes de talento humano se les aplicó una encuesta sobre información de cultura y gestión humana. Los autores pudieron identificar que las prácticas de recursos humanos están fuertemente relacionadas con la cultura organizacional.

A partir de los hallazgos encontrados, se puede afirmar que existe una relación recíproca entre la cultura organizacional y las prácticas de recursos humanos y que estas son diferentes en cada organización.

Hernández y Méndez (2012) realizaron una investigación en México para vincular la cultura y el clima organizacional. La muestra estuvo compuesta por 973 participantes que pertenecían a 11 organizaciones de distintos rubros empresariales. Los resultados obtenidos mostraron altos niveles de correlación entre clima y cultura. Además, las evidencias de validez de constructo encontradas en el instrumento revelaron que este mide las cuatro culturas y sus variables; solo se observó que el cuadrante de jerarquía tenía un nivel de validez menor que el resto. Todo ello obedece a lo sugerido por Cameron y Quinn (2006) con respecto de que las empresas estudiadas presentaron una mezcla en todos los cuadrantes y no se concentraron solo en una o algunas.

Otro estudio, también realizado en la ciudad de México por Núñez, Mercado y Banegas (2015), tenía como objetivo analizar la relación de la cultura organizacional flexible y rígida con el capital intelectual. Se obtuvo como resultado que las culturas rígidas como las de mercado y adhocrática pueden aportar al desarrollo del capital intelectual de las organizaciones. Además, por un lado, el análisis factorial confirmatorio permitió agrupar a los tipos de cultura en los cuadrantes respectivos. Por otro lado, los 4 factores presentaron los siguientes alfa de Cronbach: Clan .937, Adhocrática .893, Jerárquica .904 y de Mercado .891, esto quiere decir que también se verificó satisfactoriamente la confiabilidad del instrumento. 
Abbasi, Sajjadi y Kazemnejad (2013) hicieron un estudio el cual consistió en validar las propiedades psicométricas del OCAI en 253 deportistas iraníes. Los resultados obtenidos muestran que dicho cuestionario es un modelo multidimensional y los cuatro factores representados por los tipos de cultura, fueron encontrados. Además, se confirmó una confiabilidad a través del alfa de Cronbach de .86. Basándose en esos resultados se concluyó que el OCAI basado en el modelo de MVC es apropiado para medir la cultura organizacional.

Por último, en una investigación coreana llevada a cabo por Heritage, Pollock y Roberts (2014) se analizaron las propiedades psicométricas del OCAI estableciendo equivalencias culturales a través de un análisis factorial confirmatorio, para lo cual la prueba fue sometida a validez de contenido según expertos quienes hicieron el método back translation y concluyeron que los 24 ítems eran apropiados para medir la cultura organizacional. Los coeficientes de confiabilidad en la versión en inglés fluctúan entre .79 y .92, mientras que en la versión coreana los coeficientes fluctúan entre .78 y .92. Además, se halló que existen correlaciones significativas entre todos los tipos de cultura.

Dentro de las investigaciones nacionales encontradas, Vargas (2009) realizó un estudio en el departamento de Puno cuyo propósito era conocer la cultura subyacente que motiva e impulsa el comportamiento de los docentes. Los principales hallazgos encontrados muestran que las variables de "cultura" y "desarrollo universitario" se encuentran asociadas y que el conocimiento de la cultura organizacional permitirá conocer mejor y contribuirá al desarrollo universitario expresado en valores positivos con relación a la identidad, compromiso social, profesionalismo y laboriosidad de los docentes; y por el lado contrario, la falta de responsabilidad y ambigüedad en el compañerismo.

Estos hallazgos nos permiten comprender que el concepto de cultura organizacional es transversal a las organizaciones y también se puede medir a un nivel educativo. 


\section{CAPÍTULO III: OBJETIVOS Y DEFINICIÓN DE VARIABLES}

\subsection{Objetivos}

\subsubsection{Objetivo General}

Adaptar las propiedades psicométricas del Organizational Culture Assesment Instrument en una muestra de trabajadores del sector público y privado en Lima Metropolitana.

\subsubsection{Objetivos Específicos}

Determinar las propiedades psicométricas del OCAI al:

a) Obtener evidencias de validez vinculadas al contenido de la versión en español del OCAI mediante criterio de jueces.

b) Obtener evidencias de validez de estructura interna de la versión en español del OCAI mediante el análisis factorial exploratorio.

c) Obtener evidencias de confiabilidad de las puntuaciones derivadas de los ítems que conforman el OCAI mediante el método de consistencia interna.

d) Obtener la capacidad discriminativa de los ítems del OCAI mediante la correlación ítem test corregida.

\subsection{Definición de variables}

\subsubsection{Definición conceptual de Cultura Organizacional}

La cultura organizacional es el patrón de valores y creencias compartidas entre los miembros de una organización los cuales ayudan a entender su funcionamiento y sirven como pautas que determinan la conducta de los colaboradores (Deshpandé y Webster, 1989). La cultura organizacional es el conjunto de supuestos implícitos que se comparten y se dan por sentado, sostenido por un grupo de personas y que determina cómo perciben, piensan y reaccionan ante diversas dificultades (Schein, 1986).

Según Cameron y Ettington (1988) la cultura es un núcleo perdurable y de lento cambio como atributo de las organizaciones, la cual se refiere a aspectos implícitos de las organizaciones. Es por ello, que la cultura incluye los valores principales y un consenso en la interpretación de porqué las cosas son como son. 
El Modelo de Valores en Competencia adopta la definición de cultura de manera funcional, según la disciplina sociológica en la que mencionan que las organizaciones poseen una cultura. La cultura es tratada como un atributo de la organización que puede ser medida independientemente de esta.

\subsubsection{Definición Operacional de Cultural Organizacional}

El constructo de cultura organizacional puede ser definido operacionalmente en función a los 24 ítems que componen el instrumento a aplicar (Cameron y Quinn, 2006). Estos están agrupados en 6 dimensiones:

- Características dominantes: Son las características dominantes de la organización o cómo es en general.

- Liderazgo Organizacional: Es el estilo de liderazgo o el enfoque que adquiere la organización.

- Gerencia de Empleados: La gestión de los empleados o el estilo que caracteriza cómo los empleados son tratados y cómo es el ambiente laboral.

- Cohesión Organizacional: Son los ejes estratégicos que definen las áreas de énfasis que manejan la estrategia de la información.

- Criterios de Éxito: Son los criterios de éxito que determinan como el triunfo es definido y que es lo que se recompensa y que es lo que se celebra.

Con ellos se forman los cuatro tipos de cultura: Clan, Adhocrática, Jerárquica y Mercado, las cuáles se encuentran ubicados en cada uno de los 4 cuadrantes y así se determina qué tipo de cultura organizacional posee la compañía. 


\section{CAPÍTULO IV: MÉTODO}

\subsection{Tipo y diseño de investigación}

La presente investigación es de tipo psicométrica ya que a partir de las puntuaciones obtenidas en la aplicación del OCAI se han determinado las propiedades psicométricas del instrumento en mención, siendo estas evidencias de confiabilidad y evidencias de validez vinculadas a la estructura interna y vinculadas al contenido (Alarcón, 2008).

El alcance es descriptivo porque busca especificar propiedades y características importantes de cualquier fenómeno que se analice. Para efectos de este estudio, se pretende especificar propiedades, características y rasgos de la cultura organizacional en un grupo de personas que se encuentran laborando en Lima Metropolitana (Hernández et al., 2014). Este tipo de estudio ayudará a describir con mayor precisión las dimensiones de un fenómeno.

Asimismo, el diseño de investigación, tomado de Hernández et al. (2014), es no experimental porque el estudio se va a realizar sin la manipulación intencionada de variables y solo se observan situaciones ya existentes en su ambiente natural para luego analizarlos y es transversal descriptivo ya que la recogida de datos se hará en un momento único y las variables son netamente descriptivas.

\subsection{Participantes}

Los participantes laboran en distintas empresas privadas y públicas en Lima Metropolitana de diferentes rubros, los cuales fueron agrupados en: servicio, manufactura, transporte, consumo e industria. El número de encuestados asciende a 211 trabajadores administrativos que ocupan posiciones desde asistentes hasta puestos gerenciales. La recolección de datos está dirigida a esa población.

Se utilizó una muestra no probabilística porque el procedimiento de selección de estuvo determinado por características como: edad, sexo, tiempo de permanencia en la empresa, área y rubro, por lo tanto, el muestreo tuvo carácter intencional. Además, es no representativa de los trabajadores administrativos de Lima Metropolitana (Hernández et al., 2014).

El criterio utilizado para mantener una muestra adecuada se obtuvo a través del estudio de MaCallum, Widaman, Zhang y Hong (1999) ya que a partir de realizar un 
experimento Monte Carlo, a fin de recuperar de manera adecuada la estructura factorial poblacional con variables continuas, concluyen que se requiere 100 casos si las comunalidades son altas (superiores a .50) y se tienen por lo menos 10 variables por cada factor. En este estudio, la comunalidad más baja obtenida es de .50, la más alta es de .82 y se alcanzó más de 10 variables por cada factor, es por ello que se aceptó la muestra de 211 colaboradores.

El instrumento fue aplicado a 211 personas que trabajan a tiempo completo, es decir, a partir de 40 horas o más a la semana y se excluyó a practicantes o personas que no cumplan con dicha jornada y a los que laboran de manera independiente. Con relación sociodemográficos alcanzados, el 52.61\% de la muestra tomada era de género masculino, mientras que un $47.39 \%$ de la muestra fue de género femenino. Además, se midió el tiempo de permanencia en la organización cuyo promedio fue de 39 meses, es decir, 3.25 años.

Es importante enfatizar la importancia de una muestra heterogénea porque a partir de ella se maximiza la varianza de las variables relevantes según el constructo de interés (Fabrigar, Wegener, MacCallum y Strahan, 1999, p. 272).

En la tabla 4.1 se detalla la distribución de la muestra según los datos sociodemográficos explicados anteriormente. 
Tabla 4.1

Distribución de la muestra según variables sociodemográficas

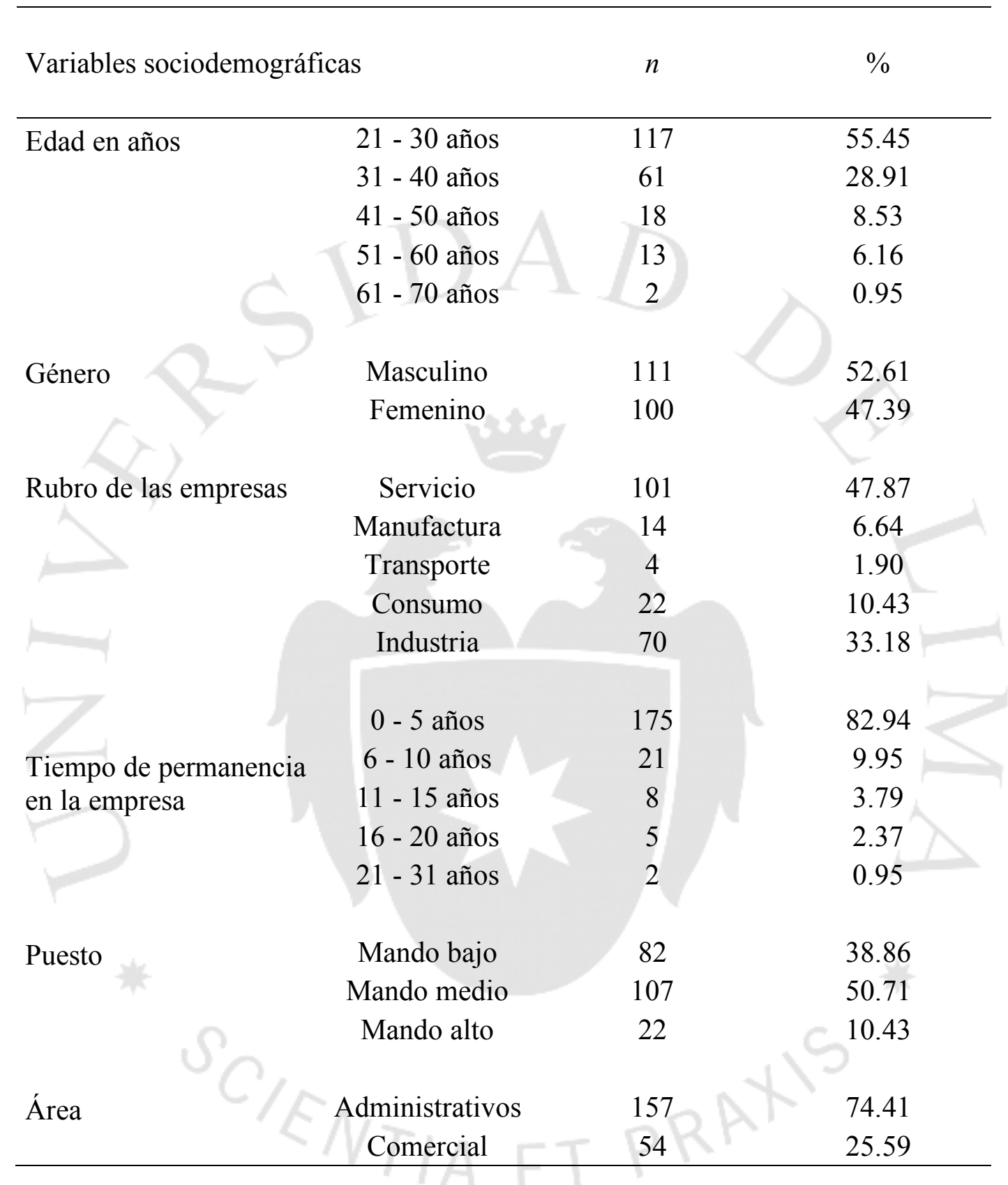

\subsection{Técnicas de recolección de la información}

Para llevar a cabo esta investigación, se utilizó como herramienta de evaluación el instrumento denominado Organizational Culture Assessment Instrument (OCAI) el cual fue acompañado de una ficha sociodemográfica para complementar la investigación e incluye variables como: edad, género, rubro de las empresas, tiempo de permanencia, puesto y área. 
El OCAI es un instrumento estandarizado desarrollado para la medición y diagnóstico de la cultura organizacional dirigida a cualquier persona que se encuentre laborando. Su aplicación puede darse de manera grupal o individual y se realiza de manera sencilla, rápida (ya que puede tardar hasta 20 minutos en responder) y es de fácil comprensión. La prueba consta de 24 ítems distribuidos en 6 dimensiones: Características Dominantes, Liderazgo organizacional, Gestión de Empleados, Cohesión organizacional, Énfasis Estratégico y Criterios de Éxito, las cuáles han sido detalladas en el Capítulo II: Marco Teórico.

Como se mencionó anteriormente, el OCAI consta de seis dimensiones, cada una de ellas tiene cuatro alternativas. Para efectos de la puntuación, la versión original maneja una escala de medida ipsativa o también llamada de elección forzada. La tarea consiste en dividir 100 puntos entre estas cuatro opciones en función al grado en que cada alternativa es similar a su propia organización. La idea principal es dar un mayor número de puntos a la alternativa que más se asemeja a su organización. Por ejemplo, en la pregunta uno, si uno piensa que la alternativa A es muy similar a su organización, la variante $\mathrm{B}$ y $\mathrm{C}$ son algo similares, y alternativa $\mathrm{D}$ es casi similar en todos, es posible dar 55 puntos a $\mathrm{A}$, a 20 puntos de $\mathrm{A}$ a $\mathrm{B}$ y $\mathrm{C}$ y cinco puntos a $\mathrm{D}$, sólo hay que asegurarse de que su total es igual a 100 puntos para cada dimensión. Hay que tener en cuenta que la sección de "Ahora" se refiere a la cultura tal y como se percibe hoy en día. El criterio "Ahora" se refiere al conjunto de suposiciones, conductas, historias, mitos y otros supuestos que se reúnen para definir lo que significa ser un colaborador de la compañía en el presente. Después de completar esa columna, encontrará las mismas preguntas para calificar la sección "Preferencia" la cual se refiere a cómo le gustaría que la organización fuera en 5 años. Este criterio se refiere al conjunto de suposiciones, conductas, historias, mitos y otros supuestos que se reúnen para definir lo que significa ser un colaborador de la compañía deseada. En el anexo 2 se muestra la prueba original traducida al español enviada por el mismo autor para el presente estudio.

Para efectos de esta investigación, se modificó la escala de medida ipsativa para dar paso a la escala Likert (1932) en el cual los encuestados debían asignar una puntuación del 1(Muy en desacuerdo) al 5 (Muy de acuerdo) para cada ítem. Esto se pensó y se realizó por temas de practicidad, ya que es una de las escalas más utilizadas para calificar instrumentos en el ámbito organizacional. De esta manera, se modificó la forma de presentar el cuestionario tal como se puede observar en el Anexo 3. Adicionalmente, se agregó una columna al costado de la evaluación de la cultura Actual 
para puntuar la cultura Deseada, eso se hizo para una mejor visualización de los ítems y se pueda llegar comparar mejor las diferencias entre ambas opciones.

En un estudio realizado por Quinn y Spreitzer (1991) en el que participaron 796 ejecutivos de 86 diferentes firmas públicas se obtuvieron los siguientes coeficientes de confiabilidad por cada dimensión: Clan .74, Adhocracia .79, Jerarquía .73 y Mercado .71. En otro estudio realizado por Yeung, et. al (1991), se tuvo una muestra de 10,300 ejecutivos en 1,064 empresas. Los resultados por cada dimensión muestran lo siguiente: Clan .79, Adhocracia .80, Jerarquía .76 y Mercado .77. Asimismo, encontraron que el $44 \%$ de las empresas predominaba una cultura burocrática, seguidos de Clan y Adhocracia con 15 y 14\% respectivamente y, por último, ninguno estaba dominado por la cultura de Mercado.

Después de ver estos resultados de las puntuaciones derivadas de los ítems del instrumento, los autores llegaron a la conclusión que se tiene suficiente evidencia para asegurar la confiabilidad del OCAI.

A la fecha, algunos de los estudios peruanos encontrados que han utilizado esta herramienta fueron realizadas por Díaz, Sánchez, Villacorta y Vivanco (2010) y el estudio de Almeyda, Arauco, La Matta, Sava y Sifuentes (2013). El primero tenía como objetivo hallar evidencias de validez de las puntuaciones derivadas de los ítems que conforman el instrumento y así estandarizarlo, sin embargo, el análisis factorial arrojó solo un factor, es decir, solo un tipo de cultura. Para alcanzar ese resultado se utilizaron diferentes muestras, en la primera versión se utilizó una escala ipsativa, como en la versión original del OCAI, sin embargo, los coeficientes de alfa de Cronbach obtenidos fueron menores a los esperados ya que el resultado fluctuó entre .29 y .57. Finalmente, en la última versión, se decidió usar la escala Likert y se obtuvo un coeficiente alfa de Cronbach de .72 a .81. Aun así, la prueba no pudo ser estandarizada.

En una investigación realizada por Kalliath, Bluedorn y Gliesper (1999), reportaron excelentes índices de consistencia interna (Alpha de Cronbach >.80) para cada uno de los factores. Uno de las mayores limitantes según lo que hicieron fue que su muestra estuvo compuesta por supervisores de staff. En resumen, validaron los cuatro factores, sin embargo, no tenían una muestra representativa de la muestra. También utilizó la escala likert.

En otro estudio donde se estudió las propiedades psicométricas del OCAI llevado a cabo por Helfrich, Li, Mohr, Meterko y Sales (2007), se realizó también un análisis factorial confirmatorio con una muestra mucho más grande de 72000 participantes. La 
consistencia interna de 3 factores fue satisfactoria, excepto por el tipo burocrática en la cual se obtuvo menos de .69. En el análisis factorial confirmatorio, los resultados no apoyaron los 4 factores, sino solo 2 factores.

\subsection{Procedimiento de recolección de datos}

En primer lugar, se utilizó una versión en español del OCAI que fue enviada directamente por el mismo autor, luego de explicarle el objetivo del estudio y posteriormente tener su aprobación. Para validar el contenido de los ítems en dicho cuestionario, se recurrió a once jueces expertos en el área organizacional, con conocimientos en cultura organizacional y con experiencia laboral de más de 10 años en áreas afines.

Primero, se elaboró para los jueces una carta de presentación donde se explicó los objetivos del estudio, las instrucciones y el instrumento a utilizar. A través de la plantilla Juicio de Expertos (Ver Anexo 4), los jueces tuvieron que determinar la relevancia, congruencia y coherencia de cada uno de los ítems en base a las definiciones mencionadas respondiendo a una pregunta dicotómica de Sí o No (se ha transformado Sí al valor 1 y No al valor 0). Por último, se insertó una columna adicional para que puedan agregar observaciones de presentarse el caso. Este proceso se dio a través del uso del correo electrónico para facilitar la gestión del tiempo, tanto del juez como del investigador.

Luego de procesar los resultados se observó que había ítems que todavía no alcanzaban la mínima puntuación (.82) necesaria para validarla, entonces para la segunda aplicación de criterio de jueces se modificaron algunas palabras del cuestionario sugeridas por los mismos expertos y nuevamente las oraciones fueron revisadas por la misma cantidad de personas que en la primera ronda y se logró obtener más de la puntuación requerida (.90).

Por último, se generó una plantilla del instrumento en un documento protegido en excel y fue así como se distribuyó a través del correo electrónico a los participantes. Se accedió a los encuestados a través de referencias, medios sociales como Facebook, LinkedIn y centros de trabajo, invitándolos a participar de la encuesta de manera voluntaria. Asimismo, se les resaltó el anonimato de la prueba para evitar resistencias en la evaluación y también se adjuntó el consentimiento informado (Anexo 6).

La aplicación se dio entre los meses de diciembre y enero, fue de manera individual y duró aproximadamente entre 15 y 20 minutos contestarla según lo que comentaron los encuestados. 


\section{CAPÍTULO V: RESULTADOS}

\subsection{Análisis psicométrico}

Después de aplicar la encuesta, se tabuló la información recogida y se elaboró una base de datos para realizar el análisis estadístico correspondiente con ayuda del programa SPSS versión 22 y el programa de análisis Factor (Lorenzo-Seva y Ferrando, 2015) para llevar a cabo el análisis factorial exploratorio. Todo ello con el fin de hallar las propiedades psicométricas y descriptivas del instrumento OCAI.

Para determinar las propiedades psicométricas del OCAI primero se hallaron las evidencias de validez vinculadas al contenido mediante criterio de jueces a través del coeficiente $\mathrm{V}$ de Aiken, luego se dispuso a hallar la evidencia de validez vinculada a la estructura interna mediante el análisis factorial exploratorio. Además, se evaluó la confiabilidad mediante el método de consistencia interna.

Adicionalmente, se obtiene la discriminación de los ítems de la prueba OCAI mediante la correlación ítem - test corregida. Se complementarán los resultados de la prueba con apoyo los datos sociodemográficos recogidos.

\subsection{Evidencias de validez vinculadas al contenido}

Según el American Educational Research Association, el American Psychological Association y el National Council on Measurement in Education (AERA, APA y NCME, 2014), la validez se refiere al grado en que la evidencia y la teoría apoyan las interpretaciones de las puntuaciones en los tests. Uno de ellos es la evidencia de validez vinculada al contenido, la cual representa la congruencia entre el contenido del test y el dominio del rango que debe medir.

Las evidencias de validez vinculadas al contenido de los ítems del OCAI, se realizaron mediante valoraciones cuantitativas a once jueces. El criterio de selección de los expertos estuvo determinado por su experiencia en el tema de cultura organizacional, no solo a nivel de conocimiento, sino también como experiencia mínima de 10 años en temas organizacionales.

Se solicitó a los jueces valorar la medida en que los ítems responden de acuerdo a los siguientes aspectos: Congruencia, si el ítem se relaciona con el indicador, dimensión y variable que se pretende medir o describir; Claridad, si la redacción del ítem facilita su comprensión; y Relevancia, si el ítem es esencial o relevante para la investigación. Las 
opciones de respuesta se presentaron de manera dicotómica, utilizando "Si" y "No" para cada ítem. Para mayor detalle, todo ello se puede visualizar en la plantilla "Formato para validar instrumento con juicios de expertos" en el Anexo $\mathrm{N}^{0} 5$.

Luego de que los jueces valoren los ítems de acuerdo a la congruencia, claridad y relevancia de cada ítem, se calcularon los puntajes obtenidos mediante el coeficiente $\mathrm{V}$ de Aiken (Aiken, 1985). De acuerdo con Escurra (1988) para hallar al V de Aiken se halla un índice en el cual se computa la razón de un dato obtenido sobre la suma máxima de la diferencia de los valores posibles. Siendo la fórmula la siguiente:

$$
\mathrm{V}=\frac{\mathrm{S}}{(\mathrm{n}(\mathrm{c}-1))}
$$

Siendo:

$\mathrm{S}=$ La sumatoria de $\mathrm{Si}$

$\mathrm{S} 1=$ Valor asignado por el juez $\mathrm{i}$

$\mathrm{n}=$ Número de jueces

$\mathrm{c}=$ Número de valores de la escala de valoración.

El número de expertos para este estudio estuvo compuesto por once jueces, por lo tanto, para esta cantidad de expertos (Aiken, 1985) se necesita el acuerdo de por lo menos 9 de ellos para que a un nivel de $\mathrm{p}<.05$ el ítem sea considerado válido. De acuerdo a este estudio y teniendo en cuenta el número de ítems, en este caso 24 , y la categoría de clasificación, la cual fue dicotómica, el coeficiente para determinar si el ítem es válido o no debe ser menor a .82 .

Se obtuvieron resultados estadísticamente significativos para el coeficiente $\mathrm{V}$ de Aiken a un nivel de $\mathrm{p}<.05$ y un coeficiente total de .97. En conclusión, el resultado de la evidencia de validez vinculada al contenido luego de la revalidación, muestra que los veinticuatro ítems presentados a los once jueces fueron aceptados como congruentes, claros y relevantes del constructo al que representan. 
Tabla 5.1

Evidencias de validez vinculadas al contenido de las puntaciones del OCAI

\begin{tabular}{lccc}
\hline Ítem & $\mathrm{V}$ & Ítem & $\mathrm{V}$ \\
\hline $\mathrm{i} 1$ & $1.00^{*}$ & $\mathrm{i} 13$ & $1.00^{*}$ \\
$\mathrm{i} 2$ & $.93^{*}$ & $\mathrm{i} 14$ & $1.00^{*}$ \\
$\mathrm{i} 3$ & $.97^{*}$ & $\mathrm{i} 15$ & $.97^{*}$ \\
$\mathrm{i} 4$ & $1.00^{*}$ & $\mathrm{i} 16$ & $.97^{*}$ \\
$\mathrm{i} 5$ & $1.00^{*}$ & $\mathrm{i} 17$ & $1.00^{*}$ \\
$\mathrm{i} 6$ & $1.00^{*}$ & $\mathrm{i} 18$ & $.97^{*}$ \\
$\mathrm{i} 7$ & $.97^{*}$ & $\mathrm{i} 19$ & $1.00^{*}$ \\
$\mathrm{i} 8$ & $.97^{*}$ & $\mathrm{i} 20$ & $.97^{*}$ \\
$\mathrm{i} 9$ & $.93^{*}$ & $\mathrm{i} 21$ & $.97^{*}$ \\
$\mathrm{i} 10$ & $.97^{*}$ & $\mathrm{i} 22$ & $.97^{*}$ \\
$\mathrm{i} 11$ & $.93^{*}$ & $\mathrm{i} 23$ & $.97^{*}$ \\
$\mathrm{i} 12$ & $.97^{*}$ & $\mathrm{i} 24$ & $.97^{*}$ \\
$\mathrm{~V}$ total & $.97^{*}$ & & \\
\hline$* p<.05$ & & & \\
\hline
\end{tabular}

\subsection{Evidencias de validez vinculadas a la estructura interna}

La evidencia basada en la estructura interna de la prueba se refiere a la consistencia entre la estructura del constructo y las relaciones entre los ítems y/o subescalas del test (AERA et al., 2014).

A través del análisis factorial exploratorio (AFE) se determinó la evidencia de validez vinculada a la estructura interna del OCAI. El análisis factorial exploratorio es el método más utilizado para explorar las propiedades psicométricas de un instrumento ya que busca extraer factores latentes de las variables medibles. Este modelo reconoce la varianza y única a través de variables (Osborne, 2015). Este análisis se ejecutó a través de una matriz de correlaciones policóricas ya que las variables trabajadas en el presente estudio son de tipo ordinal (con escalas politómicas) (Burga, 2006).

Se halló la medida de adecuación muestral de Kaiser Meyer-Olkin (KMO), la cual analiza el tamaño de las correlaciones parciales entre las variables. En este caso se obtuvo una medida de .92 siendo este número mayor al de lo esperado ya que se suele aconsejar valores de preferencia mayores a .60 (Ferrando y Anguiano-Carrasco, 2010), lo cual indica que la correlación de los ítems es lo suficientemente alta para ejecutar el AFE. Por otro lado, se utilizó el test de esfericidad de Bartlett con el cual se comprobó la existencia 
de correlaciones estadísticamente significativas entre los ítems del instrumento $X^{2}$ $(2675.4)=276, \mathrm{p}<.001$. Por consiguiente, tanto el KMO como el Test de Esfericidad de Barlett señalaron que los datos son adecuados para hacer el análisis factorial.

El AFE se llevó a cabo sobre los 24 ítems que conforman el OCAI. Luego se dio paso a hallar la rotación, la cual tiene como objetivo simplificar y clarificar la estructura de la data y para efectos de este estudio se usó el método oblicuo el cual permite a los factores correlacionarse (Costello y Osborne, 2005) y se utilizó una rotación de tipo Promin, para mejorar la interpretabilidad de los factores (Lorenzo - Seva, 1999). La factorización de la matriz de correlaciones se ejecutó mediante una correlación policórica ya que la escala de medición utilizada es de tipo ordinal siendo Likert la escala de valorización.

Con respecto al método de extracción, se utilizó el método Minimun Rank Factor Analysis (MRFA sigas en inglés) para la extracción de factores y el análisis paralelo el cuál determinó el número de factores a retener, en este caso fueron 2. Según Timmeman y Lorenzo-Seva (2011), se usa el método MRFA para trabajar con matrices de correlaciones policóricos, como es el caso. Además, se utilizó este método de extracción debido a que en un estudio de simulación se mostró que este método es una buena elección para la identificación del número de factores comunes. Con esto se descarta la posibilidad de mantener los 4 factores con los que fue construida la prueba en un inicio. En la tabla 5.2 se muestra la estructura inicial del OCAI según el AFE aplicado. 
Tabla 5.2

Análisis factorial exploratorio de los items del OCAI con dos factores rotados de forma oblicua.

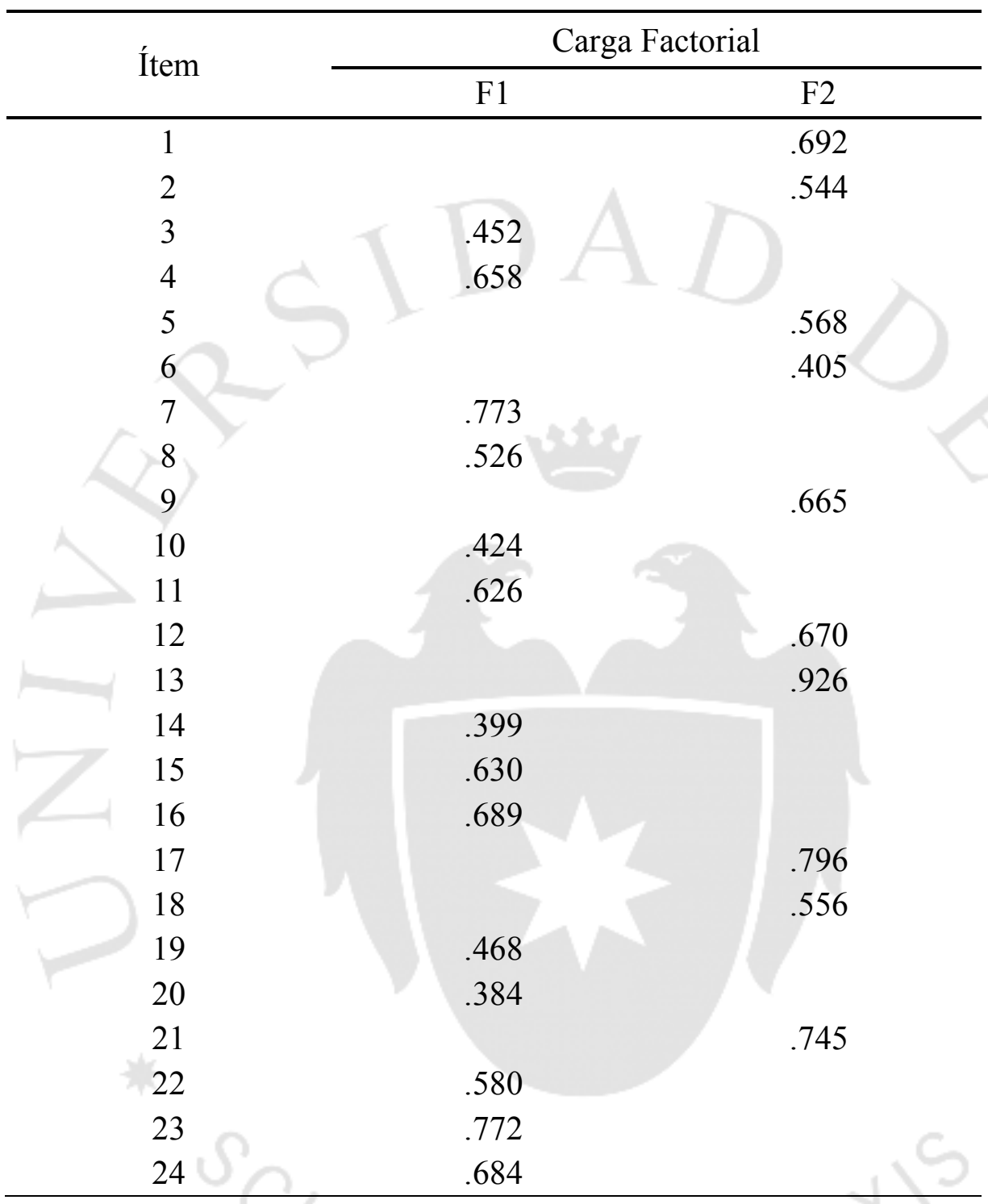

Para una mejor claridad en la interpretación de los resultados de la tabla 5.3, se eliminaron los ítems con cargas factoriales menores a .30.

Como se mencionó líneas arriba, el programa Factor sugirió dos factores, por ello se realizó una matriz para identificar qué ítems estaban siendo identificados por factor.

\subsection{Análisis de la discriminación de los ítems del OCAI}

Para hallar la discriminación de los 24 ítems que componen la estructura bidimensional del OCAI encontrada en este estudio, se realizó el análisis de correlación ítem-total 
corregido. La discriminación de un ítem tiene como objetivo diferenciar los ítems alto de los que puntúan bajo en una prueba (Morales, 2009).

Se puede observar que los puntajes obtenidos superan el valor mínimo aceptado de .20 (Everitt y Skrondal, 2010), con lo cual se confirma que la prueba OCAI presenta adecuados coeficientes de correlación ítem-test corregido e indica que todos los ítems permiten discriminar entre los participantes que puntúan alto y bajo en cada dimensión. Los resultados del análisis se muestran en la tabla 5.3 a continuación.

Tabla 5.3

Análisis de discriminación de los items del OCAI para el Factor 1

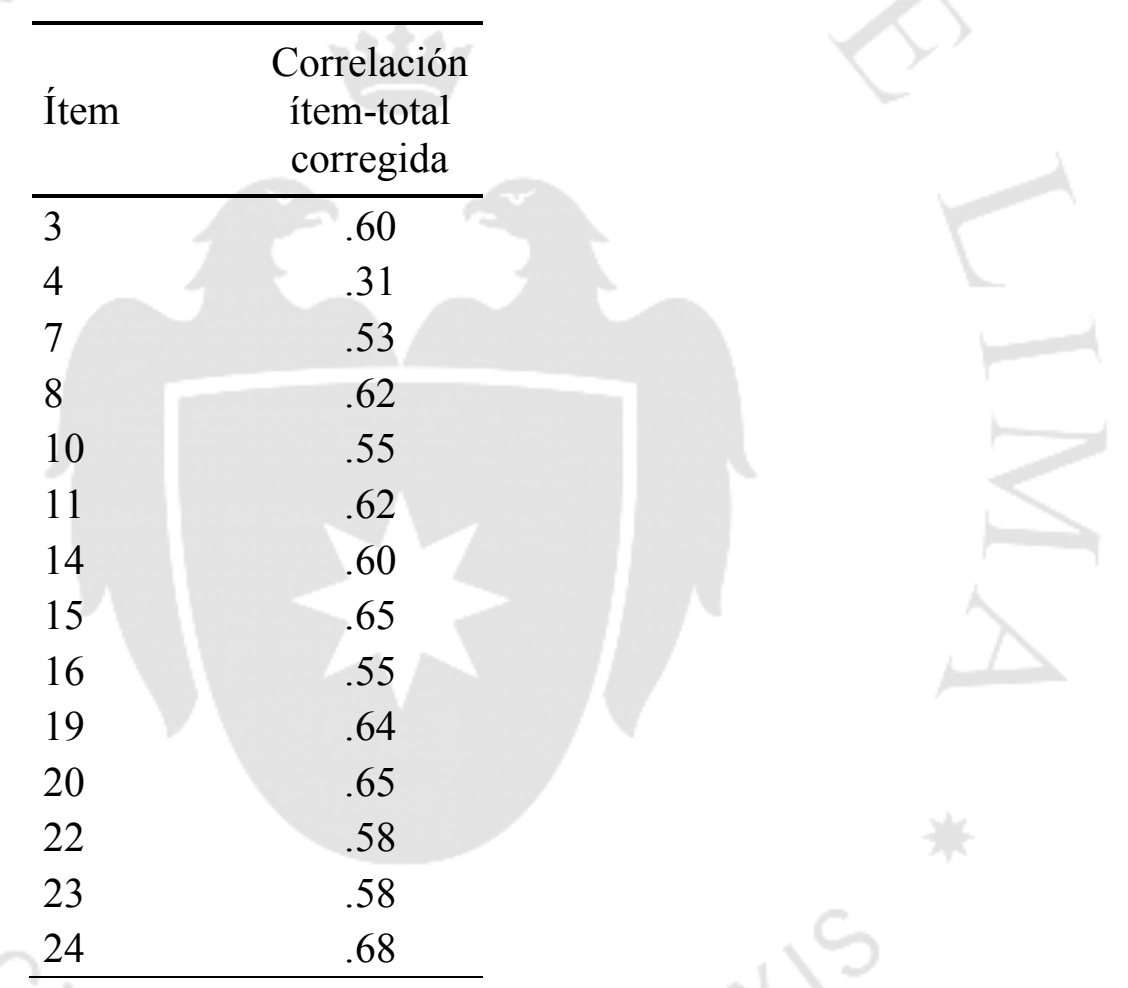


Tabla 5.4

Análisis de discriminación de los ítems del OCAI para el Factor 2

\begin{tabular}{lc}
\hline Ítem & $\begin{array}{c}\text { Correlación } \\
\text { ítem-total } \\
\text { corregida }\end{array}$ \\
\hline 1 & .44 \\
2 & .57 \\
5 & .68 \\
6 & .74 \\
9 & .58 \\
12 & .60 \\
13 & .58 \\
17 & .66 \\
18 & .64 \\
21 & .71 \\
\hline
\end{tabular}

5.5 Estimación de la confiabilidad de las puntuaciones derivadas de la aplicación de los ítems que conforman el OCAI

Para estimar la confiabilidad de las puntuaciones derivadas del OCAI, se realizó el método de consistencia interna hallando el coeficiente Alpha Ordinal y alfa de Cronbach. Según Zumbo, Gadermann y Zeisser (2007), el primero, estima la confiabilidad de manera más exacta que el Alpha de Cronbach para escala de respuestas binarias y ordinales y en este estudio estamos utilizando la escala tipo Likert, para ello se basa en una matriz policórica.

Además, se calculó el error estándar de medición (EEM) a partir de los valores alfa de ordinales que se obtuvieron de las puntuaciones derivadas de los ítems del OCAI. El coeficiente alcanzado por dicho método superó el valor mínimo aceptado para un coeficiente de confiabilidad, es decir, .70 (Celina y Campo, 2005; Kline, 1999; Nunnally y Bernstein, 1995).

Los valores obtenidos son calificados como altos y solo se necesitó de la ejecución de un solo análisis puesto que el valor obtenido es óptimo. 
Tabla 5.5

Alfa de Cronbach, Alfa Ordinal y EEM para las puntuaciones derivadas de los items del $O C A I$

\begin{tabular}{lccc}
\hline \multicolumn{4}{c}{ Estadísticas de fiabilidad } \\
\hline & Alfa de Cronbach & Alfa Ordinal & EEM \\
Factor 1 (11 ítems) & .90 & .89 & 2.66 \\
Factor 2 (9 ítems) & .88 & .86 & 2.38 \\
& & & \\
\hline
\end{tabular}

\subsection{Análisis descriptivo de las puntuaciones del OCAI}

El análisis descriptivo de las puntuaciones del OCAI obtenidas en la muestra de estudio $(N=211)$ revelan un puntaje medio de 45.18 para el primer factor y 31.33 para el segundo factor y una desviación estándar de 9.49 y 7.65 respectivamente.

En la tabla 5.6 se muestran los estadísticos descriptivos de las puntuaciones obtenidas que corresponden a la aplicación del OCAI.

Tabla 5.6

Estadísticos descriptivos de las puntuaciones obtenidas correspondientes a la aplicación del OCAI

\begin{tabular}{lcccccc} 
& Mín & Máx & Me & M & DE & $\begin{array}{c}\text { 95\% (IC de } \\
\text { la media) }\end{array}$ \\
\hline Factor 1 (14 ítems) & 14 & 55 & 37 & 35.85 & 7.68 & {$[34.08,36.89]$} \\
Factor 2 (10 ítems) & 12 & 43 & 30 & 28.28 & 6.87 & {$[27.35,29.22]$}
\end{tabular}

Nota: $\mathrm{N}=211 ; 24$ ítems 


\section{CAPÍTULO VI: DISCUSIÓN}

Para empezar, se analizará y discutirá los resultados alcanzados como producto del análisis psicométrico del Organizational Cuestionnaire Assessment Instrument (OCAI), la cual se enfocará en las propiedades psicométricas y en los estándares de pruebas psicológicas con los que cumple de acuerdo a Estándares para la Evaluación Educativa y Psicológica (AERA et al., 2014).

Finalmente, se analizará e interpretarán los resultados descriptivos teniendo en cuenta las variables sociodemográficas.

\subsection{Análisis de las propiedades psicométricas del Organizational Culture Assesment Instrument (OCAI)}

El instrumento está estructurado en función al Modelo de Valores en Competencia (MVC) de Cameron y Quinn quienes desarrollaron el cuestionario y con el cuál se compararán resultados obtenidos en la propuesta inicial y la propuesta obtenida a partir del análisis psicométrico aplicados.

Con respecto a las evidencias de validez vinculadas al contenido de las puntuaciones derivadas del OCAI, todos los ítems fueron aceptados como representativos del constructo que pretenden medir ya que muestran altos niveles de consistencia interna logrando un coeficiente de .97 en la $\mathrm{V}$ de Aiken cuando el mínimo requerido era de .82 (Aiken, 1985).

Es importante mencionar que, para llegar a obtener tales resultados, en la fase de evidencias de validez vinculada al contenido se tuvieron que modificar 7 ítems del documento original (los números fueron: 2, 3, 5, 7, 12, 18 y 19) para que, luego de la segunda vuelta con los jueces expertos, estas pudieran ser validadas.

En contraste, estas evidencias no concordaron con los resultados basados en la estructura interna del modelo original pues ese sugiere una estructura de 24 ítems con 4 factores (los cuáles responden a los 4 tipos de cultura que presenta el modelo teórico de los autores) y lo obtenido son dos factores.

Una de las ventajas de la prueba es que es sencilla de aplicar, puede ser aplicada de manera individual como grupal y consta solo de 24 ítems, por lo que no es extensa y gracias a ello es rápida de responder. Además, es útil para proporcionar un diagnóstico de la cultura organizacional y hallar la brecha entre la cultura actual y la deseada. 
Por el contrario, algunas de las desventajas que posee el cuestionario es que utilizaba conectores en los enunciados lo que dificultaba y confundía la comprensión de estos.

Por otra parte, los coeficientes alcanzados a través del método Alfa de Cronbach en el Factor $1(\alpha=.90)$, Alfa de Cronbach en el Factor $2(\alpha=.88)$, Alfa Ordinal Factor $1(\alpha=.89)$ Alfa Ordinal Factor $2(\alpha=.86)$ garantizaron la confiabilidad de las puntuaciones derivadas del OCAI, tomando en cuenta la estructura final compuesta por 24 ítems. Adicionalmente, todos los ítems indicaron ser discriminativos ya que presentaron una correlación ítem-total corregida mayor a .20 (Kline, 1986) lo que significa que la prueba produce resultados consistentes y coherentes (Hernández et al., 2014). Para complementar dicha información, el OCAI ha presentado coeficientes de Cronbach similares, es decir, de .91 en una investigación realizada en México (Hernández y Méndez, 2012). Asimismo, a diferencia de los instrumentos utilizados anteriormente, el OCAI es el único cuya confiabilidad de las puntuaciones ha sido estimada utilizando el coeficiente de alfa ordinal. Es importante y necesario utilizar este coeficiente debido a que están en función a una escala Likert, los cuales cuentan con un formato de respuesta politómica y miden variables ordinales (Bonanomi et al., 2013; Gadermann et al., 2012; Zumbo et al., 2007).

Como resultado general de las evidencias empíricas mostradas, se puede afirmar que las interpretaciones que se realicen a partir de la aplicación del OCAI son válidas y confiables. Es así que se puede inferir que el OCAI es una herramienta útil, que brinda información importante acerca de la brecha entre la cultura organizacional actual y la deseada, la cual permite tomar decisiones que afectarían de manera positiva la estrategia del negocio.

\subsection{Estándares para la Evaluación Educativa y Psicológica (AERA, APA y NCME,} 2014)

A continuación, se detallarán los estándares para la evaluación para pruebas psicológicas que corresponden al presente estudio y con los que cumple el instrumento utilizado, el OCAI. Cada categoría enumerada hace referencia a la validez, confiabilidad, equidad, diseño y desarrollo de instrumentos y a la documentación adjunta para el instrumento. 


\subsubsection{Estándares para la validez}

1.0 "Debe ser presentada una articulación clara de cada interpretación propuesta de las puntuaciones de la prueba para un uso específico y se debe proveer evidencias de validez apropiadas para cada interpretación que se desee formular” (p. 23):

El OCAI tiene la finalidad de diagnosticar y modificar la cultura organizacional para ejecutar cambios en el desempeño de los colaboradores. Este fue diseñado a partir del modelo teórico MVC el cual ayuda a identificar de manera sistemática qué cosa se debe incrementar, disminuir y qué deberá permanecer constante para acortar las brechas entre la cultura actual y la cultura deseada, por lo cual, el propósito de este estudio es analizar y determinar las propiedades psicométricas de la prueba OCAI en trabajadores del sector privado y público en Lima Metropolitana. De esta manera, con este instrumento se va a poder identificar la fuerza, congruencia y tipo de cultura en las organizaciones en Lima de manera válida y confiable. De manera que, en relación al OCAI, se proporcionaron las evidencias de validez apropiadas vinculadas al contenido, a la estructura interna y a la relación con otras variables, las cuales fueron reportadas en la sección de Resultados.

1.1 "El creador de la prueba debe describir con claridad la manera en la cual los puntajes de la prueba se interpretarán y utilizarán. La población para la cual la prueba fue propuesta debe delimitarse claramente y el constructo o constructos que la prueba pretende evaluar deben describirse con claridad" (p. 23): Las puntuaciones derivadas de la aplicación del OCAI reflejan la percepción de la cultura organizacional de los colaboradores según dos tipos de cultura. La población se delimitó claramente en la sección de Método, específicamente en la subsección de Participantes. El constructo que la prueba pretende evaluar es la cultura organizacional, la cual se definió con claridad en la sección de objetivos y definición de variables.

1.6 Cuando el uso de una prueba es recomendado para producir beneficios indirectos, adicionalmente a la utilidad de la información de la interpretación de las puntuaciones de la prueba, se debe proveer argumentos teóricos y evidencia empírica que lo fundamenten así como hallazgos contradictorios o distintos a los esperados (p. 24): Se recomienda el uso del OCAI para describir la percepción de los colaboradores acerca de la cultura organizacional y a partir de ello predecir la congruencia, fuerza y el tipo de cultura predominante. Al identificar este último, se 
puede ejecutar un plan de acción para identificar la cultura actual y deseada para acortar la brecha entre ambas y obtener una ventaja competitiva sobre otras organizaciones, tal como se mencionó en la sección de Marco Teórico. La utilidad de diagnosticar y hacer un cambio cultural tiene 6 ventajas, entre ellas está: la practicidad, el tiempo, el involucramiento, maneja dos niveles de medición: cuantitativa y cualitativa y es válida (Cameron y Quinn, 2001).

1.8 La composición de cualquier muestra de participantes a partir de la cual se obtienen las evidencias de validez debe ser descrita con el mayor detalle posible, incluyendo las características sociodemográficas y de desarrollo más relevantes (p. 25): La muestra de estudio fue seleccionada mediante un muestreo no probabilístico y por conveniencia. Ésta estuvo compuesta por 211 trabajadores de empresas públicas y privadas que radican en Lima Metropolitana, excluyendo a trabajadores independientes y practicantes debido a que no están involucrados en la cultura debido a su alta rotación. La edad de los participantes oscilaba entre los 22 y $\operatorname{los} 71$ años siendo el promedio 32.37 , de los cuáles el $52.61 \%$ eran hombres y el $47.39 \%$ eran mujeres. Estas y otras características sociodemográficas y de desarrollo se especificaron en la sección de Método.

1.9 Cuando la validación depende de las opiniones o decisiones de jueces expertos, se deben describir los procedimientos para seleccionarlos y para registrar sus juicios, se deben de presentar las calificaciones y experiencia de los jueces e incluir cualquier entrenamiento o instrucciones dadas, así como su grado de acuerdo (p. 25): En la sección de Resultados, con la finalidad de obtener evidencias de validez vinculadas al contenido, se especificó el procedimiento para la calificación del OCAI por once jueces. Los jueces convocados pertenecían a diferentes especialidades: profesores con experiencia en el área organizacional, cultura organizacional y psicólogos expertos en psicometría. A partir de sus calificaciones, se obtuvo un coeficiente $\mathrm{V}$ de Aiken de .97, el cual superó el grado de acuerdo mínimo de .82. Se puede consultar el Anexo 5 para observar la matriz que completaron los jueces.

1.10 Cuando las evidencias de validez incluyen análisis estadísticos de los resultados de la prueba, las condiciones en las cuales los datos fueron recolectados deben ser descritas de manera detallada (p. 26): El proceso a partir del cual se realizó la recolección de datos utilizando el OCAI se explica de manera detallada en la sección 
de Método, incluyendo tanto los pasos que se siguieron como las condiciones en las cuales se dio la aplicación del instrumento.

1.13 Si el fundamento para la interpretación de las puntuaciones de la prueba para un uso particular depende de premisas sobre la relación entre los ítems de la prueba o entre las partes de la prueba, se debe proveer evidencias respecto a la estructura interna de la prueba (p. 27): En la sección de Resultados, se estimaron las evidencias de validez vinculadas a la estructura interna del OCAI mediante la realización de un AFE y se reportó una estructura bidimensional de la prueba que explica el $48.23 \%$ de la varianza acumulada en ambos factores retenidos.

\subsubsection{Estándares para la confiabilidad}

2.0 Evidencias de confiabilidad apropiadas deben ser provistas para la interpretación de cada uso de las puntuaciones (p. 42): Como se menciona en la sección de Resultados, se reportaron coeficientes de confiabilidad altos para las puntuaciones de ambos factores obtenidos de la estructura bidimensional.

2.3 Para cada puntaje total, subpuntaje y combinación de puntajes que son interpretados, se deben reportar índices relevantes de confiabilidad (p. 43): En la sección de Resultados se reportaron adecuadamente los coeficientes de confiabilidad para las puntuaciones totales del OCAI, así como para ambos factores encontrados y se consideraron los coeficientes alfa de Cronbach y alfa ordinal.

2.5 Los procedimientos de estimación de la confiabilidad deben ser consistentes con la estructura de la prueba (p. 43): Tal y como se reporta en la sección de Resultados, luego de realizar el AFE se obtuvo una estructura bidimensional del OCAI, por lo cual la estimación de la confiabilidad se realizó únicamente en función a las puntuaciones totales de los dos factores compuestos por 24 ítems.

2.13 El EEM, tanto general como condicional (en caso haya sido reportado), debe proveerse en unidades para cada puntaje reportado (p. 45): El EEM ha sido debidamente reportado en la sección de Resultados, tanto para la estimación del coeficiente de confiabilidad alfa de Cronbach y alfa ordinal como para las puntuaciones totales de los dos factores obtenidos en la muestra total del OCAI. 


\subsubsection{Estándares para la administración, puntuación e interpretación}

6.1 Los evaluadores deben seguir cuidadosamente los procedimientos para la administración y puntuación especificados por el creador de la prueba y otras instrucciones del usuario de la prueba (p. 114): La aplicación se dio de manera virtual y tanto en el correo electrónico enviado, así como en la carta de presentación adjunta los participantes fueron debidamente informados sobre los procedimientos de administración del OCAI para que puedan ser replicados con exactitud. El procedimiento de recabación de las puntuaciones fue llevado a cabo únicamente por la administradora de la prueba.

6.4 El ambiente de evaluación debe ser cómodo y con mínimas distracciones para evitar varianza irrelevante al constructo (p. 116): Se aseguró que la aplicación de las pruebas se realizara en ambientes similares, como una tablet, computadora o laptop, en donde los participantes se sientan cómodos y libres de sesgos para poder responder adecuadamente a la prueba.

\subsection{Interpretación de las puntuaciones del OCAI en función a investigaciones anteriores}

Con respecto a los resultados encontrados, se muestra que los ítems de la prueba OCAI no están representando los 4 tipos de cultura que deberían y esto se puede visualizar claramente en el análisis factorial cuando las puntuaciones derivadas de los ítems sólo cargan en dos factores.

A manera de integrar los ítems por factor, encontramos que en el Factor 1 están cargados 14 ítems $(3,4,7,8,10,11,14,15,16,19,20,22,23$ y 24), los cuales están representados, en su mayoría, por los tipos de cultura Jerárquica y de Mercado, a excepción de los ítems 10, 14 y 22 que pertenecen al tipo de cultura Adhocrática tal como se observa en la siguiente tabla: 
Tabla 6.1

Distribución de items en el factor 1

\begin{tabular}{|c|c|c|}
\hline ítem & Tipo de Cultura & Descripción \\
\hline 3 & Jerárquica & $\begin{array}{l}\text { La organización está muy orientada hacia resultados. Una } \\
\text { preocupación principal es realizar el trabajo cumpliendo con } \\
\text { los estándares solicitados. Las personas son muy } \\
\text { competitivas y orientadas al logro. }\end{array}$ \\
\hline 4 & Mercado & $\begin{array}{l}\text { La organización es un lugar muy controlado y estructurado. } \\
\text { Por lo general los procedimientos formales gobiernan lo que } \\
\text { la gente hace. }\end{array}$ \\
\hline 7 & Jerárquica & $\begin{array}{l}\text { El liderazgo en la organización es por lo general considerado } \\
\text { como ejemplo de un enfoque audaz, orientado hacia los } \\
\text { resultados y que deja de lado lo que no tiene importancia } \\
\text { directa sobre dichos resultados. }\end{array}$ \\
\hline 8 & Mercado & $\begin{array}{l}\text { El liderazgo en la organización es por lo general considerado } \\
\text { como ejemplo de eficiencia en la coordinación, la } \\
\text { organización y el desarrollo sin contratiempos. }\end{array}$ \\
\hline 10 & Adhocrática & $\begin{array}{l}\text { El estilo gerencial de la organización está caracterizado por } \\
\text { adopción individual de riesgos, innovación, libertad y } \\
\text { excelencia. }\end{array}$ \\
\hline 11 & Jerárquica & $\begin{array}{l}\text { El estilo gerencial de la organización está caracterizado por } \\
\text { alta competitividad, altas demandas y logros. }\end{array}$ \\
\hline 14 & Adhocrática & $\begin{array}{l}\text { Lo que une a la organización es el compromiso con la } \\
\text { innovación y el desarrollo. Se hace énfasis en estar a la } \\
\text { vanguardia. }\end{array}$ \\
\hline 15 & Jerárquica & $\begin{array}{l}\text { Lo que une a la organización es el énfasis en los logros y la } \\
\text { realización de objetivos. La audacia y el deseo de vencer son } \\
\text { temas comunes. }\end{array}$ \\
\hline 16 & $\mathrm{~N}$ & $\begin{array}{l}\text { Lo que une a la organización es el conjunto de reglas y } \\
\text { políticas formales. Es importante mantener una organización } \\
\text { que funcione sin contratiempos. }\end{array}$ \\
\hline 19 & Jerárquica & $\begin{array}{l}\text { La organización hace énfasis en promover acciones } \\
\text { competitivas y consecución inmediata de resultados. }\end{array}$ \\
\hline
\end{tabular}




\begin{tabular}{lll}
\hline $20 \quad$ Mercado & $\begin{array}{l}\text { La organización hace énfasis en la permanencia y la } \\
\text { estabilidad. Son importantes la eficiencia, el control y la } \\
\text { fluidez de las operaciones. }\end{array}$ \\
$22 \quad$ Adhocrática & $\begin{array}{l}\text { La organización define el éxito sobre la base de contar con el } \\
\text { mejor producto. Es líder en el producto y en su innovación. }\end{array}$ \\
& Jerárquica & $\begin{array}{l}\text { La organización define el éxito sobre la base de vencer y } \\
\text { mantenerse a distancia de la competencia. El liderazgo } \\
\text { competitivo es clave. }\end{array}$ \\
& $\begin{array}{l}\text { La organización define el éxito sobre la base de la eficiencia. } \\
\text { La entrega confiable y los cronogramas sin contratiempos } \\
\text { son elementos críticos. }\end{array}$ \\
&
\end{tabular}

De la misma manera, en el Factor 2 se cargaron 10 ítems $(1,2,5,6,9,12,13,17,18,21)$ los cuales en su mayoría pertenecían a los tipos de cultura Clan y Adhocrática a excepción del ítem 12 que pertenece al tipo de cultura Mercado tal como se observa en la siguiente tabla: 
Tabla 6.2

Distribución de items en el factor 2

\begin{tabular}{|c|c|c|}
\hline ítem & Tipo de Cultura & Descripción \\
\hline 1 & Clan & $\begin{array}{l}\text { La organización es un lugar muy personal. Es como una } \\
\text { familia. Las personas parecen compartir mucho entre ellos. }\end{array}$ \\
\hline 2 & Adhocrática & $\begin{array}{l}\text { La organización es dinámica y emprendedora. Las personas } \\
\text { están dispuestas a hacer valer sus ideas y tomar riesgos. }\end{array}$ \\
\hline 5 & Clan & $\begin{array}{l}\text { El liderazgo en la organización es por lo general considerado } \\
\text { como ejemplo de guía, que orienta y brinda entrenamiento. }\end{array}$ \\
\hline 6 & Adhocrática & $\begin{array}{l}\text { El liderazgo en la organización es por lo general considerado } \\
\text { como ejemplo de mentalidad empresarial, innovación o } \\
\text { adopción de riesgos. }\end{array}$ \\
\hline 9 & Clan & $\begin{array}{l}\text { El estilo gerencial de la organización está caracterizado por } \\
\text { trabajo en equipo, consenso y participación. }\end{array}$ \\
\hline 12 & Mercado & $\begin{array}{l}\text { El estilo gerencial de la organización está caracterizado por } \\
\text { brindar seguridad, estabilidad y protección a las personas. }\end{array}$ \\
\hline 13 & Clan & $\begin{array}{l}\text { Lo que une a la organización es la lealtad y la confianza mutua. } \\
\text { El compromiso con esta organización es una prioridad. }\end{array}$ \\
\hline 17 & Clan & $\begin{array}{l}\text { La organización hace énfasis en el desarrollo humano. } \\
\text { Persisten altos niveles de confianza, franqueza y participación. }\end{array}$ \\
\hline 18 & Adhocrática & $\begin{array}{l}\text { La organización hace énfasis en adquirir nuevos recursos y } \\
\text { crear nuevos retos. Se valora el intentar cosas nuevas y } \\
\text { explorar posibilidades futuras como oportunidades. }\end{array}$ \\
\hline 21 & Clan & $\begin{array}{l}\text { La organización define el éxito sobre la base del desarrollo del } \\
\text { recurso humano, trabajo en equipo, compromiso de sus } \\
\text { empleados e interés por las personas. }\end{array}$ \\
\hline
\end{tabular}

Como se ha mencionado anteriormente, en otras investigaciones nacionales se ha encontrado que, luego de hacer el análisis factorial se tuvo como resultado un marco unifactorial, lo que contradice a lo encontrado en el presente estudio, así como con el 
marco teórico original; sin embargo, en investigaciones internacionales se encontraron evidencias de haber obtenido 4 factores que corresponden a los 4 tipos de cultura que presenta el modelo teórico MVC del OCAI.

En este estudio, el instrumento muestra tener factores independientes por la representación de los ítems. Se esperaba que la correlación entre factores sea casi cero o de 0.30; sin embargo, se encontró que ascendían a 0.70 lo que demuestra que los ítems no están siendo claramente identificados o distinguidos por los encuestados. A continuación, se detallan algunas de las razones por las que se considera haber obtenido los resultados presentados:

Con respecto a la veracidad de los datos, se identificó una limitación en la posibilidad de respuestas con sesgo que brindan los encuestados, debido a la deseabilidad social natural frente a la resolución del cuestionario OCAI, aun cuando para minimizar el impacto de este efecto la encuesta fue anónima y no se consignó el nombre de la empresa.

Con respecto a la muestra, observamos una limitación en la acotada disponibilidad que mostraban los participantes para completar el cuestionario de manera presencial, dentro de un momento y lugar determinado por el investigador. Para minimizar el impacto de esta limitación se optó por enviar el cuestionario de manera electrónica, evitando que el participante se traslade y facilitándole que ejecute el cuestionario en el momento y lugar de su elección, sin embargo, la desventaja de esta metodología es que no recibes los resultados de manera inmediata y esto genera que el proceso se dilate más.

También se considera que los resultados de las puntuaciones derivadas obtenidas se pueden explicar debido a un problema en el marco conceptual de la prueba, a pesar que en investigaciones internacionales anteriores se han obtenido resultados satisfactorios como los mencionados anteriormente. En otros estudios, la muestra estuvo compuesta en su mayoría por docentes, personal administrativo e incluso personal laborando en el campo de la salud. En este caso se obtuvo una muestra similar, no obstante, la muestra puede haber estado sesgada por deseabilidad social al responder la prueba, igualmente el colaborador puede no haber estado consciente de la cultura de su organización, es por ello que el encuestado encontró difícil identificar y diferenciar debido a la confusión de los ítems.

Otra manera de verlo puede ser que la muestra solo identifique dos factores porque a grandes rasgos es así como la muestra percibe su cultura organizacional. En un artículo realizado por Hartnell, Yi Ou y Kinicki (2011), concluyeron que, si bien encontraron 
apoyo en evidencias de validez, no respaldan aspectos de la estructura interna del MVC, por ello, proponen un enfoque teórico alternativo que calzaría de una mejor manera con los resultados encontrados en el presente estudio. Sugieren no limitarse a un solo tipo de cultura dominante porque de ser el caso, no tendrían en cuenta el ancho de banda de la cultura organizacional ya que estas incluyen aspectos múltiples de diferentes tipos de cultura que se forman como resultado de una interacción sinérgica con los valores.

Adicionalmente, la idea es entender qué hay detrás de la cultura organizacional, es decir, la cultura de cada limeño. El vicepresidente de Desarrollo Ejecutivo de Linkedin, Kofman (2015), comenta que en el Perú y Latinoamérica existe una cultura paternalista cuando debería ser participativa, proactiva; la idea es que los colaboradores se alineen a los objetivos de la organización no por el hecho de obedecer, sino por alcanzar metas en común. Según lo mencionado, se espera que los líderes puedan ejecutar un modelo de liderazgo que inspire compromiso entre sus miembros. Los resultados del presente estudio podrían reflejar una falta de compromiso con el líder y esa falsa percepción afectar la interpretación de los ítems.

Sería interesante realizar un estudio en empresas emergentes limeñas y de provincias; Morales (2016) comentó en un artículo el probable inicio de cómo surgieron los emprendedores de clase baja como consecuencia del terrorismo en el país. Esta cultura informal se manifiesta por generar sus propias reglas. Nuevamente, la cultura adhocrática se podría describir de manera más abierta en pequeñas empresas en clases emergentes.

A partir de todo lo mencionado, son varios factores los que pueden explicar el que no se representaran los cuatro tipos de cultura, entre ellos, el marco conceptual, el tipo de muestra o el criterio de selección y sobretodo la cultura del país, por ello es necesario seguir adaptando los instrumentos a las necesidades de diferentes contextos para generar un entendimiento general de la cultura organizacional a fin de analizar y construir más relaciones entre las variables. 


\section{CONCLUSIONES}

Con respecto al análisis psicométrico del Organizational Culture Assesment Instrument (OCAI):

- Con respecto a las evidencias de validez vinculadas a la estructura interna, el Organizational Cuestionaire Assesment Instrument (OCAI) no replicó la estructura factorial propuesta por Cameron y Quinn (1999). Los resultados no guardan concordancia con el marco teórico original.

- El análisis psicométrico cumple con los requisitos de los Estándares para la Evaluación Educativa y Psicológica (AERA, APA y NCME, 2014) en relación a los criterios de validez, confiabilidad y para la administración, puntuación e interpretación del OCAI.

- Se confirma la presencia de evidencias de validez vinculadas al contenido de las puntuaciones derivadas del OCAI, respaldadas por el criterio de 11 jueces quienes aceptaron la estructura multidimensional de la prueba calificando a los ítems como congruentes, claros y relevantes del constructo que se procura medir. No obstante, el análisis de la estructura interna a partir del AFE evidenció una estructura bidimensional del OCAI contrario a lo propuesto inicialmente por los autores creadores de la prueba.

- Se comprueba la existencia de evidencias de confiabilidad de las puntuaciones obtenidas de la aplicación OCAI en la muestra representativa ya que se obtuvieron coeficientes de confiabilidad por encima de .88, tanto en alfa de Cronbach como en alfa ordinal.

- La versión final del OCAI muestra una estructura factorial bidimensional compuesta por 24 ítems. 
- La estructura bidimensional compuesta por 24 ítems presenta una discriminación ítem - total corregida, lo cual significa que todos los ítems están siendo discriminados.

- Los hallazgos obtenidos se diferencian de la investigación peruana realizada por Díaz, M. et al., (2010) porque la estructura factorial de su estudio era unidimensional, mientras que la del presente estudio es bidimensional.

- Considerando los resultados obtenidos, se puede comprueba que existen evidencias de validez y confiabilidad para los usos e interpretaciones producto de la aplicación del OCAI en trabajadores del sector público y privado en Lima Metropolitana. La generalización de los resultados expuestos se limita a los trabajadores que compartan características similares a los de la muestra utilizada, de lo contrario se deberá realizar nuevamente la estimación de las propiedades psicométricas pertinentes. 


\section{RECOMENDACIONES}

A continuación, se detallarán las recomendaciones:

- Analizar las propiedades psicométricas del Organizational Culture Assesment Instrument en nuevas poblaciones de Lima y Provincia, tomando en cuenta la utilidad de la prueba en el ámbito educativo como instituciones superiores, el ámbito clínico, como instituciones de salud y el ámbito social en organizaciones sin fines de lucro, o en empresas del mismo rubro, donde se pueda ver reflejada una cultura mejor consolidada.

- Prescindir del OCAI para medir la cultura organizacional de las empresas porque los resultados encontrados no reflejan los 4 tipos de cultura propuestos por el autor.

- Buscar otros instrumentos de medición como el Cuestionario de cultura organizacional de Denison, el cual no se encuentra estandarizado actualmente en Lima, sin embargo, es una buena oportunidad para adaptarlo.

- Incluir otras variables como nivel de educación, percepción de la cultura del área, el nivel de conocimiento de la cultura.

- Ejecutar un análisis factorial confirmatorio considerando una muestra mucho más amplia con el fin de obtener los cuatro factores correspondientes a cada tipo de cultura para adaptar el instrumento y así obtener una muestra más heterogénea.

- Utilizar un muestreo probabilístico para realizar comparaciones entre variables con el fin de aumentar la validez externa y generalizabilidad de los resultados. 
- Proponer una nueva interpretación del modelo teórico alineado con la cultura peruana ya que es probable que la muestra solo haya identificado dos factores porque es así como esta percibe la cultura en su organización.

- Incorporar más herramientas de medición para el diagnóstico de la cultura organizacional, empezando por un estudio cuantitativo y luego pasar a un enfoque cualitativo para complementar los resultados en próximas investigaciones. El primero permitirá sondear las percepciones de los colaboradores, mientras que con el segundo se podrán ahondar estos resultados.

- Desarrollar futuros estudios correlacionales que intenten explicar los tipos de cultura en relación a variables como tiempo de permanencia en la empresa, número de colaboradores, áreas como servicio al cliente, y los mencionados anteriormente.

- Elaborar baremos de las puntuaciones derivadas obtenidas de la aplicación del OCAI de acuerdo a variables sociodemográficas que permitan inferir la percepción de la cultura organizacional.

- Elaborar y ejecutar programas que faciliten el cambio o fusión cultural de las organizaciones, previamente teniendo conocimiento de la cultura actual y la deseada. 


\section{REFERENCIAS}

Abbasi H, Sajjadi S N, \& Kazemnejad A. (2013) Validation of the Organizational culture Assessment Instrument (OCAI) based on the Competing Values Framework Model (CVF) within Iranian Sport Organizations (Federations); 3(5), 85-97 Recuperado de http://jrsm.khu.ac.ir/article-1-1762-en.html.

Aguirre, A (2000). La Cultura de las organizaciones. Anthropologica, 5(6), 1-203.

Aguirre, A. (2002). La Cultura de la empresa. Revista Malestar e Subjetividade, 2(2), 86122.

Aguirre, A. (2004). La cultura de las organizaciones. Barcelona-España: Editorial Ariel.

Aiken Lewis, R. (1985). Three coefficients for analyzing the reliability, and validity of ratings. Educational and Psychological Measurement, 45(1), 131 - 142.

Alarcón, R. (2008). Métodos y diseño de investigación del comportamiento (2da ed). Lima, Perú: Universidad Ricardo Palma.

Almeyda, C. C., Arauco, P. M., La Matta, A., Sava, M.B. y Sifuentes, R. C. (2013). Diagnóstico y propuesta de Modelo de Cultura Organizacional para establecimientos penitenciarios a cargo del Instituto Nacional Penitenciario (tesis de maestría). Recuperado de http://repositorio.esan.edu.pe/handle/esan/5193

American Educational Research Association (AERA), American Psychological Association (APA), \& National Council of Measurement in Education (NCME). (2014). Standards for educational and psychological testing. Washington, DC: AERA.

Bantz Charles, R. (1993). Understanding organizations: Interpreting Organizational communicating cultures. Columbia: University of South Carolina Press.

Barney, J. (1986) Organizational culture: Can it be a source of sustained competitive advantage? Academy of Management Review, 11(3) 656-665. Recuperado de http://www.jstor.org/stable/258317 
Berg, P.O (1986). Symbolic management of human resources. Human resources management, 25, 557-559. Recuperado de http://dx.doi.org/10.1002/hrm.3930250406

Bolívar, Botía. A. (1993). Culturas profesionales en la enseñanza. Cuadernos de pedagogía, 219, 68-72.

Bonanomi, A., Ruscone, M. N., \& Osmetti, S. A. (2013). The Polychoric Ordinal Alpha, measuring the reliability of a set of polytomous ordinal items. In Advances in Latent Variables-Methods, Models and Applications. Recuperado de http://meetings.sisstatistica.org/index.php/sis2013/ALV/paper/viewFile/2651/42 4

Burga, A. (2006). La unidimensionalidad de un instrumento de medición: perspectiva factorial. Revista de Psicología de la PUCP, 24(1), 53-80. Recuperado de: http://revistas.pucp.edu.pe/index.php/psicologia/article/view/642/629

Calderón Hernández, G., Murillo Galvis, S. M. y Torres Narváez, K Y. (2003). Cultura Organizacional y bienestar laboral. Cuadernos de Administración, 16(25) 109137. Recuperado de http://www.redalyc.org/articulo.oa?id=20502506

Calderón Hernández, G. y Serna Gómez, H. (2009). Relaciones entre Cultura Organizacional. Un estudio empírico. Acta colombiana de psicología. 12(2) 97114. Recuperado de http://www.redalyc.org/articulo.oa?id=79815640010

Cameron, K. S. \& Ettington, D. R. (1988) The conceptual foundations of Organizational Culture. Higher Education: Handbook of theory and research.

Cameron, K. \& Quinn, R. (1999).

Cameron, K. (2003). Ethics, Virtuousness, and Constant Change (eds.), The Ethical Challenge. San Francisco: Jossey-Bass.

Cameron, K. S. \& Quinn, R. E. (2006). Diagnosing and changing organizational culture: Based on the completing values framework (Rev-ed). San Francisco, CA: Jossey Bass.

Cantú, H. (2001). Desarrollo de una cultura de calidad. México. Ed. McGraw Hill. 
Castillo, E. (1 de setiembre del 2012). Cultura Organizacional: ¿Cómo alinearla con la estrategia? [mensaje en un blog] Recuperado de http://www.infocapitalhumano.pe/recursos-humanos/informes/CulturaOrganizacional-como-alinearla-con-la-estrategia/

Celina, O. H. y Campos A. A. (2005). Aproximación al uso del coeficiente alfa de Cronbach. Revista Colombiana de Psiquiatría, 34(4), 572-580. Recuperado de http://redalyc.uaemex.mx/pdf/806/80634409.pdf

Clay, L, H. (1978) Introducción a la psicología social. México: Trillas.

Costello, A.B \& Osborne, J.W. (2005). Best practices in Exploratory Factor Analysis: four recommendations for getting the most from your analysis. Practical Assessment, Research \& Evaluation, 10(7), 1-9. Recuperado de http://pareonline.net/pdf/v10n7.pdf

Darcey-Lymn, M. \& Farbrother, S. (2003). Changing organizational culture one face at a time. Public Management, 85, 14.

Delobbe, N., Haccoun, R.R., Y Vandenberghe, C. (2000). Measuring core dimensions of organizational culture: a review of research and development of a new instrument. Paper presented at the Annual Conference of the Society of Industrial and Organizational Psychology, Toronto, Canada.

Denison, D., Janovics, J. \& Young, J. (2006). Diagnosing organizational cultures: Validating a Model and Method. Denison Consulting Group, 23, 1-17.

Denison, D. R., \& Spreitzer, G. M. (1991). Organizational culture and organizational development: A competing values approach. Research in organizational change and development, 5(1), 1-21.

Denison, D. \& Neale, W. S. (1996). Denison organizational culture survey: facilitator guide. Ann Arbor (MI): Aviat.

Deshpande, R. \& Webster, F.E. (1989). Organizational culture and marketing: defining the research agenda. Journal of Marketing, 53, 3-15. 
Díaz, M. M., Sánchez, P. J., Villacorta, A, K., Vivanco Q., L. (2010) Medición cuantitativa de la cultura organizacional en dos empresas en un proceso de postadquisición en Perú (tesis de maestría). Recuperada de: http://repositorio.esan.edu.pe/handle/esan/319

Díez, G. E. y Domínguez, F. G. (2002). Evaluación de la cultura en la organización de instituciones de educación social (tesis de doctorado). Universidad Complutense de Madrid. Recuperada de http://biblioteca.ucm.es/tesis/19911996/S/5/S5010801.pdf

Escurra, L.M. (1998). Cuantificación de la validez de contenido por criterio de jueces. Revista de Psicología, 6(2), 103-111. Recuperado de http://revistas.pucp.edu.pe/

Espaillatt Hernández, T. (2012). Evaluación de la Cultura Organizacional en una Institución del Estado (tesis en maestría). Instituto global de altos estudios en ciencias sociales. Recuperado de: https://docs.google.com/viewer?a=v\&pid=sites\&srcid=ZGVmYXVsdGRvbWF pbnxnZXN0aW9uYWRnZW5lc3xneDoyMGU4NmM3MDU0OWJjOWZh

Everitt, B.S. \& Skrondal, A. (2010). The cambridge dictionary of statistics (4th ed). New York: Cambridge University Press.

Fabrigar, L.R., Wegener, D.T., MacCallum, R.C. \& Strahan, R. J. (1999). Evaluating the use of exploratory factor analysis in psychological research. Psychological Methods, 4(3), 272-299. http://dx.doi.org/10.1037/1082-989X.4.3.272

Ferrando, P. J. y Anguiano-Carrasco, C. (2010). El análisis factorial como técnica de investigación en psicología. Papeles del Psicólogo, 31(1), 18-33.

Gadermann, A. M., Guhn, M., \& Zumbo, B. D. (2012). Estimating ordinal reliability for Likert-type and ordinal item response data: A conceptual, empirical, and practical guide. Practical Assessment, Research \& Evaluation, 17(3), 1-13. Recuperado de http://www.pareonline.net/getvn.asp?v=17\&n=3. 
Goffman, E. (1972) Relations in public: microstudies of the public order. New York: Basic Books.

Hartnell, C. A., Ou, A. Y., \& Kinicki, A. (2011). Organizational culture and organizational effectiveness: A meta-analytic investigation of the Competing Values Framework's theoretical suppositions. Journal of Applied Psychology, 96(4), 677-694.

Helfrich, C. D., Yu-Fang, L., Mohr, D. C., Meterko, M., \& Sales, A. E. (2007). Assessing an organizational culture instrument based on the Competing Values Framework: Exploratory and confirmatory factor analyses. Implementation Science, 2, 13-14. doi: $10.1186 / 1748-5908-2-13$

Heritage B, Pollock C. \& Roberts L. (2014). Validation of the Organizational Culture Assessment Instrument. Plos One 9(3): e92879. Recuperado de: https://doi:10.1371/ journal.pone.0092879

Hernández, S. R. y Méndez, V.S. (2012). Exploración factorial del clima y la Cultura Organizacional en el marco del modelo de los valores en competencia. Revista PsiqueMag, 1, 1-37.

Hernández, S. R., Fernández, C. C. y Baptista, L. P. (2014). Metodología de la investigación (6ta ed.). México, D.F: McGraw-Hill Education.

Hernández, R., Méndez, S. y Contreras, R. (2014). Construcción de un instrumento para medir el clima Organizacional en función del modelo de los valores en competencia. Contaduría y Administración, 59(1), 229- 257.

Hoffman David, A. \& Jones Lisa, M. (2005). Leadership, Collective Personality, and Performance. Journal of Applied Psychology, 90(3), 509-522.

Infestas Gil, A. (1991) Sociología de la empresa. Salamanca: Amar Ediciones.

Kast Freemont, E. y Rosenzweig James, E. (1987). Administración en las Organizaciones. México: Mc Graw-Hill. 
Kline, P. (1986). A Handbook of test construction: Introduction to psychometric design. London: Methuen.

Kline, P. (1999). The handbook of psychological testing ( $2^{\text {nd }}$ Ed.). London: Routledge.

Kofman, F. (2 de noviembre del 2015). LinkedIn: Cultura empresarial del Perú es muy paternalista envés de participativa [mensaje en un blog]. Recuperado de: http:/gestion.pe/empleo-management/ejecutivo-linkedin-Cultura-empresarialperu-muy-paternalista-vez-participativa-2147016

Lorenzo-Seva, U. (1999). Promin: a method for oblique factor rotation. Multivariate Behavioral Research, 34 , 347-365. http://dx.doi.org/10.1207/S15327906MBR3403_3

Lorenzo-Seva, U. y Ferrando Pere, J. (2015). Factor (Versión 10.3.1) (Software de computación). Recuperado de: http://psico.fcep.urv.es/utilitats/factor/index.html

McCallum, R.C., Widaman, K.F., Zhang, S., \& Hong, S. (1999). Sample size in factor analysis. Psychological Methods, 4(1), 84-89. http://dx.doi.org/10.1037/1082989X.4.1.84

Maldonado Guzman, G., Martínez Serna, M. y García Pérez de Lema, D. (2010). Aplicación del modelo CVF en la Pyme de aguas calientes. Un estudio empírico. Investigación y ciencia de la universidad autónoma de Aguascalientes, (50), 3339.

Lynn, M. L. (1988). Organizational culture: origins and weaknesses. Organization Studies, 9(4), 453-473.

Morales, M. A., Hernández, J., y Medina, M. V. (2009). Diagnóstico de la Cultura Organizacional en una institución de Educación Superior. UPIICSA, 18(7), 5051.

Morales, P. (2009). Análisis de los ítems en las pruebas objetivas. Madrid: Universidad Pontificia Comillas.

Morales, O. (1 de junio del 2016). La Cultura chicha y la nueva clase emprendedora [mensaje en un blog]. Recuperado de: 
https://www.esan.edu.pe/conexion/bloggers/interculturalmanagement/2016/06/la-cultura-chicha-y-la-nueva-clase-emprendedora/

Nunnally, J. C., y Bernstein, I. H. (1995). Teoría psicométrica $\left(2^{\mathrm{a}}\right.$ ed.). México D.F.: McGraw Hill.

Nuñez, R. M., Mercado, S. P., y Banegas, R. R. (2015). Relación entre Cultura Organizacional (flexible y rígida) y Capital Intelectual. Conciencia tecnológica, 49, 4-11.

Ogbonna E. \& Harris L. (2002) Managing organizational culture: Insights from the hospitality industry. Human Resource Management Journal, 12(1), 33-54.

Ogbonna E. \& Whipp, R (1999). Strategy culture and HRM: Evidence from the UK food retailing sector. Human Resource Management Journal, 9(4), 75-91.

Osborne, J. W. (2015). What is rotating in Exploratory Factor Analysis? Practical Assessment Research and Evaluation, 20 (2). Recuperado de: http://pareonline.net/getvn.asp? $\mathrm{v}=20 \& \mathrm{n}=2$

Quinn, Robert E. (1988) Beyond rational management: Mastering the Paradoxes and Competing Demands of High Performance. San Francisco: Jossey-Bass.

Quinn, R. E. \& Rohrbaugh, J. (1983). A spatial model of effectiveness criteria: Toward a competing values approach to organizational analysis. Management Science, 29, 363-377.

Quinn R, E. \& Spreitzer, G. M. (1991) The Psychometrics of the Competing Values Culture Instrument and an Analysis of the Impact of Organizational Culture on Quality of Life. Research in Organizational Change and Development, 1(5), 115142.

Quinn, R. (2000). Change the world. San Francisco: Jossey - Bass.

Real Academia Española (2014). Diccionario de la Lengua Española (23.a ed.) Madrid, España. 
Robbins S. P. (1987) Comportamiento organizacional: conceptos, controversias y aplicaciones. México: Prentice-Hall Hispanoamericana.

Robbins, S. y Jugde, R. (2013). Comportamiento organizacional. México: Prentice Hall.

Rodríguez, R. (2009). La Cultura Organizacional. Un potencial activo estratégico desde la perspectiva de la administración. Invenio: Revista de investigación académica, (22), 67-92.

Sánchez, Q. I. (2008). Desarrollo de un instrumento de medida de la cultura organizativa: un modelo confirmatorio en hoteles españoles. Revista europea de dirección y economía de la empresa, 19(1), 107-126.

Serra, R. (2004). Reestructurando empresas. Buenos Aires: Norma.

Schein E. (1988). La cultura empresarial y el liderazgo. Barcelona: Plaza y Janés.

Schein E. (1996). Leadership and organizational culture. The Leader of the future. 1, 6162.

Timmerman, M. E. \& Lorenzo-Seva, U. (2011). Dimensionality assessment of ordered polytomous items with parallel analysis. Psychological Methods, 16(2), 209-220. http://dx.doi.org/10.1037/a0023353.

Trice, H. M., \& Beyer, J. M. (1993). The cultures of work organizations. Englewood Cliffs, N.J: Prentice Hall.

Vargas Irure, R. (2011). Cultura y desarrollo organizacional en la Universidad Nacional del Altiplano en Puno. Comunicación: Revista de investigación en comunicación $y$ desarrollo, 2(2), 5-15.

Van Waveren, J. (2012). ¿Por qué la cultura organizacional es rentable? Finanzas Personales. Recuperado de http://www.finanzaspersonales.com.co/ahorro-e inversion/articulo/por-que-Cultura-Organizacional-rentable/48064

Weber, Máx. (1947). The theory of social and economic reform. New York: Free Press. 
Yeung A.K.O. Brockbank, J.W, \& Ulrich D.O (1991). Organizational culture and human resources practice: and empirical assessment. Asia-Pacific Journal of Management Research and Innovation, 5(2), 102-108.

Zaragoza Contreras, L. (2010). Cultura, identidad y etnicidad, aproximaciones al entorno multicultural: rompiendo costumbres y paradigmas cotidianos. Cuicuilco, 17(48), 149-164.

Recuperado

de:

http://www.scielo.org.mx/scielo.php?script=sci_arttext\&pid=S01851659201000 0100009\&lng=es\&tlng=es

Zumbo, B., Gadermann, A. \& Zeisser, C. (2007). Ordinal versions of coefficients alpha and theta for Likert Rating Scales. Journal of Modern Applied Statistical Methods, 6(1), 21-29. Recuperado de: http:// digitalcommons.wayne.edu/jmasm/vol6/iss/1/4 


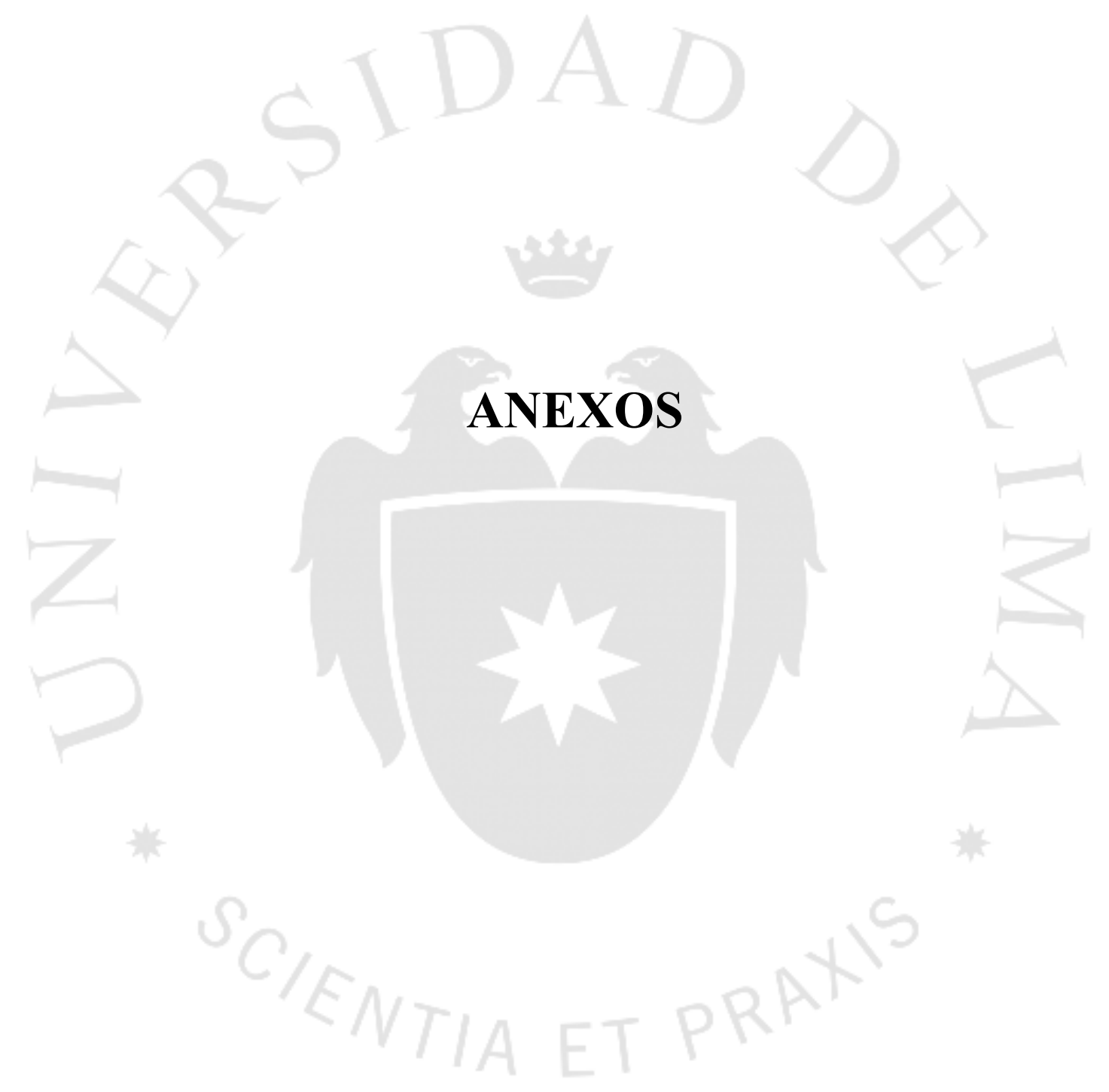




\section{ANEXO 1: Matriz organizativa del OCAI}

\begin{tabular}{|c|c|c|}
\hline Tipos de Cultura & Dimensiones & Total ítems \\
\hline \multirow{6}{*}{ Clan } & Características Dominantes & 6 \\
\hline & Liderazgo Organizacional & 6 \\
\hline & Gerencia de Empleados & 6 \\
\hline & Cohesión Organizacional & 6 \\
\hline & Énfasis Estratégico & 6 \\
\hline & Criterios de Éxito & 6 \\
\hline \multirow{6}{*}{ Adhocrática } & Características Dominantes & 6 \\
\hline & Liderazgo Organizacional & 6 \\
\hline & Gerencia de Empleados & 6 \\
\hline & Cohesión Organizacional & 6 \\
\hline & Énfasis Estratégico & 6 \\
\hline & Criterios de Éxito & 6 \\
\hline \multirow{6}{*}{ Jeráquica } & Características Dominantes & 6 \\
\hline & Liderazgo Organizacional & 6 \\
\hline & Gerencia de Empleados & 6 \\
\hline & Cohesión Organizacional & \\
\hline & Énfasis Estratégico & \\
\hline & Criterios de Éxito & 6 \\
\hline \multirow{6}{*}{ Mercado } & Características Dominantes & 6 \\
\hline & Liderazgo Organizacional & 6 \\
\hline & Gerencia de Empleados & 6 \\
\hline & Cohesión Organizacional & 6 \\
\hline & Énfasis Estratégico & 6 \\
\hline & Criterios de Éxito & 6 \\
\hline
\end{tabular}




\section{ANEXO 2: ORGANIZATIONAL CULTURE ASSESMENT}

\section{INSTRUMENT (OCAI)}

\section{Propuesta inicial}

El propósito de OCAI es evaluar las seis dimensiones clave de la cultura organizacional, no hay respuestas correctas o equivocadas para estos ítems, exactamente como no hay culturas correctas o equivocadas. Es muy probable que cada organización se describa por un conjunto diferente de respuestas. Por lo tanto, sea tan preciso como pueda al responder los ítems de manera que su diagnóstico cultural resultante será $\tan$ preciso

como sea posible.

Se le pide que clasifique a su "organización" en los ítems. Por supuesto, puede considerar varias organizaciones - su equipo inmediato, su área o la organización global. Para determinar cuál es la mejor organización para ser clasificada, considere la organización que es manejada por su jefe, la unidad de negocios estratégicos a la cual pertenece o la unidad organizacional en la cual es miembro que tiene límites claramente

identificables.

OCAI consta de seis ítems, cada uno con cuatro alternativas. Divida 100 puntos entre estas cuatro alternativas, dependiendo de la media en la que cada alternativa es similar a su propia organización. Dé un número mayor de puntos a la alternativa que es más similar a su organización. Por ejemplo, en el ítem 1, si considera que la alternativa A es muy similar a su organización, las alternativas $\mathrm{B}$ у C son algo similares y la alternativa $\mathrm{D}$ es difícilmente similar, usted podría dar 55 puntos para A, 20 puntos para B y para C, y 5 puntos para D. Sólo asegúrese de que su total es igual a 100 puntos en cada uno de los ítems.

Observe en la columna de respuesta de la mano izquierda para el instrumento se titula "Ahora". Estas respuestas indican que usted está clasificando su organización como es actualmente, no como quisiera que fuera o espera que sea. Complete esa clasificación primero. La columna de la mano derecha que se titula "Preferencia", se refiere a su organización como piensa que debe ser en cinco años con el fin de ser espectacularmente exitosa, lograr sus aspiraciones más altas, convertirse en un ejemplo sobresaliente de alto desempeño, superar las metas actualmente establecidas o volverse la referencia 
Lo invitamos a darse tiempo ahora para completar los seis ítems para su organización.

Clasifique la organización en su estado actual utilizando la columna "Ahora". Luego complete el instrumento la segunda vez utilizando la columna "Preferencia".

Es anónima, por ello le pedimos que responda con la mayor sinceridad y seriedad posible.

Sexo: F_ M

Edad:
Área a la que pertenece:

Tiempo en la empresa:

\begin{tabular}{|c|c|c|c|}
\hline \multicolumn{2}{|c|}{ 1. Características Dominantes } & Ahora & Preferencia \\
\hline $\mathrm{A}$ & $\begin{array}{l}\text { La organización es un lugar muy personal. Es como } \\
\text { una gran familia. Las personas parecen compartir } \\
\text { mucho entre ellos. }\end{array}$ & & \\
\hline $\mathrm{B}$ & $\begin{array}{l}\text { La organización es un lugar muy dinámico y } \\
\text { emprendedor. La gente está dispuesta a poner de su } \\
\text { parte y tomar riesgos. }\end{array}$ & & \\
\hline $\mathrm{C}$ & $\begin{array}{l}\text { La organización es muy orientada a los resultados. Sus } \\
\text { integrantes se preocupan mucho por realizar el trabajo. } \\
\text { La gente es muy competitiva y orientada al logro. }\end{array}$ & & \\
\hline $\mathrm{D}$ & $\begin{array}{l}\text { La organización es un lugar muy controlado y } \\
\text { estructurado. Los procedimientos formales } \\
\text { generalmente gobiernan lo que se hace. }\end{array}$ & & \\
\hline 2 & TOTAL & & \\
\hline \multicolumn{2}{|c|}{ 2. Liderazgo Organizacional } & Ahora & Preferencia \\
\hline $\mathrm{A}$ & $\begin{array}{l}\text { El liderazgo en la organización es generalmente } \\
\text { considerado como ejemplo, se encarga de guiar, } \\
\text { facilitar o fomentar las actividades. }\end{array}$ & & \\
\hline $\mathrm{B}$ & $\begin{array}{l}\text { El liderazgo en la organización se considera que } \\
\text { generalmente ejemplifica el espíritu empresarial, la } \\
\text { innovación o la asunción de riesgos. }\end{array}$ & & \\
\hline $\mathrm{C}$ & $\begin{array}{l}\text { El liderazgo en la organización es generalmente } \\
\text { considerado como ejemplo y orientado a resultados. }\end{array}$ & & \\
\hline $\mathrm{D}$ & $\begin{array}{l}\text { El liderazgo en la organización es generalmente } \\
\text { considerado como ejemplo de coordinación, } \\
\text { organización y eficiencia caracterizado por una } \\
\text { confianza mutua con el grupo de trabajo. }\end{array}$ & & \\
\hline & TOTAL & & \\
\hline \multicolumn{2}{|c|}{ 3. Gestión de Empleados } & Ahora & Preferencia \\
\hline A & $\begin{array}{l}\text { El estilo de gestión de la organización se caracteriza } \\
\text { por el trabajo en equipo, el consenso y la participación. }\end{array}$ & & \\
\hline $\mathrm{B}$ & $\begin{array}{l}\text { El estilo de gestión de la organización se caracteriza } \\
\text { por la toma de riesgo individual, la innovación y la } \\
\text { libertad. }\end{array}$ & & \\
\hline
\end{tabular}




\begin{tabular}{|c|c|c|}
\hline $\mathrm{C}$ & $\begin{array}{l}\text { El estilo de gestión de la organización se caracteriza } \\
\text { por una competencia de difícil manejo, alta demanda } \\
\text { y logros propuestos. }\end{array}$ & \\
\hline $\mathrm{D}$ & $\begin{array}{l}\text { El estilo de gestión de la organización se caracteriza } \\
\text { por la seguridad del empleo, la conformidad, la } \\
\text { previsibilidad y la estabilidad en las relaciones. }\end{array}$ & \\
\hline & TOTAL & \\
\hline \multicolumn{2}{|c|}{ 4. Cohesión Organizacional } & \\
\hline $\mathrm{A}$ & $\begin{array}{l}\text { La cohesión que mantiene unida la organización es la } \\
\text { lealtad y la confianza mutua. El compromiso con esta } \\
\text { organización es alta. }\end{array}$ & \\
\hline $\mathrm{B}$ & $\begin{array}{l}\text { La cohesión que mantiene unida la organización es el } \\
\text { compromiso con la innovación y el desarrollo. Hay un } \\
\text { énfasis en estar a la vanguardia. }\end{array}$ & \\
\hline $\mathrm{C}$ & $\begin{array}{l}\text { La cohesión que mantiene unida la organización es el } \\
\text { énfasis en el éxito y el logro de metas. }\end{array}$ & \\
\hline $\mathrm{D}$ & $\begin{array}{l}\text { La cohesión que mantiene unida la organización son } \\
\text { las reglas y políticas formales. El mantenimiento de } \\
\text { una organización que funcione sin problemas es } \\
\text { importante. }\end{array}$ & \\
\hline & TOTAL & \\
\hline \multicolumn{2}{|c|}{ 5. Énfasis Estratégico } & \\
\hline A & $\begin{array}{l}\text { La organización hace hincapié en el desarrollo } \\
\text { humano. Alta confianza, la apertura y la participación } \\
\text { persisten. }\end{array}$ & \\
\hline B & $\begin{array}{l}\text { La organización hace hincapié en el desarrollo } \\
\text { humano. Alta confianza, la apertura y la participación } \\
\text { persisten. }\end{array}$ & \\
\hline $\mathrm{C}$ & $\begin{array}{l}\text { La organización hace hincapié en las acciones de la } \\
\text { competencia y el rendimiento. Se cuenta con objetivos } \\
\text { ambiciosos y dominantes como ser líder en el } \\
\text { mercado. }\end{array}$ & \\
\hline $\mathrm{D}$ & $\begin{array}{l}\text { La organización hace hincapié en la permanencia y la } \\
\text { estabilidad. Eficiencia, control y tienen menor } \\
\text { prioridad en las operaciones que son importantes. }\end{array}$ & \\
\hline
\end{tabular}

\begin{tabular}{|l|l|l|l|}
\hline \multicolumn{2}{|l|}{ 6. Criterios de Éxito } & Ahora & Preferencia \\
\hline A & $\begin{array}{l}\text { La organización define el éxito sobre la base del } \\
\text { desarrollo de los recursos humanos, trabajo en equipo, } \\
\text { el compromiso con los empleados y la preocupación } \\
\text { por la gente. }\end{array}$ & $\begin{array}{l}\text { La organización define el éxito sobre la base de tener } \\
\text { los productos más singulares o más recientes. Es un } \\
\text { producto líder e innovador. }\end{array}$ & \\
\hline
\end{tabular}




\begin{tabular}{|l|l|l|l|}
\hline C & $\begin{array}{l}\text { La organización define el éxito sobre la base de ganar } \\
\text { en el mercado y superando a la competencia. } \\
\text { Liderazgo en el mercado competitivo es la clave. }\end{array}$ & & \\
\hline D & $\begin{array}{l}\text { La organización define el éxito sobre la base de la } \\
\text { eficiencia. Entrega confiable, programación normal y } \\
\text { la producción de bajo costo son fundamentales. }\end{array}$ & & \\
\hline & TOTAL & & \\
\hline
\end{tabular}




\section{ANEXO 3: ORGANIZATIONAL CUESTIONAIRE ASSESSMENT INSTRUMENT (OCAI) \\ Propuesta Final}

Sí

No

Acepto participar de manera voluntaria en este estudio y de haber recibido el consentimiento informado adjunto en el correo.

ORGANIZATIONAL CULTURE ASSESMENT INSTRUMENT (J. CAMERON \& R. QUINN)

Queremos conocer cómo percibes la cultura organizacional en tu organización actualmente y cómo desearías que fuera de preferencia.

\section{Generalidades}

Edad:

Sexo:

Cargo:

Área en la que labora:

Tiempo de permanencia en la empresa (meses):

Rubro de la empresa:

\section{Instrucciones}

Siguiendo la escala donde 1 significa que la oración "No caracteriza a la empresa" hasta 5 donde "Caracteriza muy bien a la empresa", valora la medida en que los siguientes enunciados identifican la cultura Actual de la empresa y luego la cultura de Preferencia en 5 años. No hay respuestas correctas o equivocadas, solo nos interesa saber su opinión.

Sus respuestas serán tratadas con confidencialidad y no afectarán su evaluación.

\begin{tabular}{|l|c|c|c|c|}
\hline $\begin{array}{l}\text { No } \\
\text { caracteriza a } \\
\text { la empresa }\end{array}$ & $\begin{array}{c}\text { Caracteriza } \\
\text { poco a la } \\
\text { empresa }\end{array}$ & $\begin{array}{c}\text { Caracteriza } \\
\text { medianamente } \\
\text { a la empresa }\end{array}$ & $\begin{array}{c}\text { Caracteriza } \\
\text { bien a la } \\
\text { empresa }\end{array}$ & $\begin{array}{c}\text { Caracteriza } \\
\text { muy bien a la } \\
\text { empresa }\end{array}$ \\
\hline 1 & 2 & 3 & 4 & 5 \\
\hline
\end{tabular}




\begin{tabular}{|c|c|c|c|}
\hline \multicolumn{2}{|r|}{ 1. Características Dominantes } & \multirow[t]{2}{*}{ Ahora } & \multirow[t]{2}{*}{ Preferencia } \\
\hline A & $\begin{array}{l}\text { La organización es un lugar muy personal. Es como } \\
\text { una familia. Las personas parecen compartir mucho } \\
\text { entre ellos. }\end{array}$ & & \\
\hline $\mathrm{B}$ & $\begin{array}{l}\text { La organización es dinámica y emprendedora. Las } \\
\text { personas están dispuestas a hacer valer sus ideas y } \\
\text { tomar riesgos. }\end{array}$ & & \\
\hline $\mathrm{C}$ & $\begin{array}{l}\text { La organización está muy orientada hacia resultados. } \\
\text { Una preocupación principal es realizar el trabajo } \\
\text { cumpliendo con los estándares solicitados. Las } \\
\text { personas son muy competitivas y orientadas al logro. }\end{array}$ & & \\
\hline $\mathrm{D}$ & $\begin{array}{l}\text { La organización es un lugar muy controlado y } \\
\text { estructurado. Por lo general los procedimientos } \\
\text { formales gobiernan lo que la gente hace. }\end{array}$ & & \\
\hline & TOTAL & & \\
\hline \multicolumn{2}{|c|}{ 2. Liderazgo Organizacional } & Ahora & Preferencia \\
\hline A & $\begin{array}{l}\text { El liderazgo en la organización es por lo general } \\
\text { considerado como ejemplo de guía, que orienta y } \\
\text { brinda entrenamiento. }\end{array}$ & & \\
\hline $\mathrm{B}$ & $\begin{array}{l}\text { El liderazgo en la organización es por lo general } \\
\text { considerado como ejemplo de mentalidad empresarial, } \\
\text { innovación o adopción de riesgos. }\end{array}$ & & -4 \\
\hline $\mathrm{C}$ & $\begin{array}{l}\text { El liderazgo en la organización es por lo general } \\
\text { considerado como ejemplo de un enfoque audaz, } \\
\text { orientado hacia los resultados y que deja de lado lo que } \\
\text { no tiene importancia directa sobre dichos resultados. }\end{array}$ & & \\
\hline $\mathrm{D}$ & $\begin{array}{l}\text { El liderazgo en la organización es por lo general } \\
\text { considerado como ejemplo de eficiencia en la } \\
\text { coordinación, la organización y el desarrollo sin } \\
\text { contratiempos. }\end{array}$ & & \\
\hline & TOTAL & & \\
\hline \multicolumn{2}{|c|}{ 3. Gestión de Empleados } & Ahora & Preferencia \\
\hline A & $\begin{array}{l}\text { El estilo gerencial de la organización está } \\
\text { caracterizado por trabajo en equipo, consenso y } \\
\text { participación. }\end{array}$ & & \\
\hline $\mathrm{B}$ & $\begin{array}{l}\text { El estilo gerencial de la organización está } \\
\text { caracterizado por adopción individual de riesgos, } \\
\text { innovación, libertad y excelencia. }\end{array}$ & & \\
\hline $\mathrm{C}$ & $\begin{array}{l}\text { El estilo gerencial de la organización está } \\
\text { caracterizado por alta competitividad, altas demandas } \\
\text { y logros. }\end{array}$ & & \\
\hline $\mathrm{D}$ & $\begin{array}{l}\text { El estilo gerencial de la organización está } \\
\text { caracterizado por brindar seguridad, estabilidad y } \\
\text { protección a las personas. }\end{array}$ & & \\
\hline & TOTAL & & \\
\hline \multicolumn{2}{|c|}{ 4. Cohesión Organizacional } & Ahora & Preferencia \\
\hline
\end{tabular}




\begin{tabular}{|c|c|c|c|}
\hline $\mathrm{A}$ & $\begin{array}{l}\text { Lo que une a la organización es la lealtad y la } \\
\text { confianza mutua. El compromiso con esta } \\
\text { organización es una prioridad. }\end{array}$ & & \\
\hline $\mathrm{B}$ & $\begin{array}{l}\text { Lo que une a la organización es el compromiso con la } \\
\text { innovación y el desarrollo. Se hace énfasis en estar a } \\
\text { la vanguardia. }\end{array}$ & & \\
\hline $\mathrm{C}$ & $\begin{array}{l}\text { Lo que une a la organización es el énfasis en los logros } \\
\text { y la realización de objetivos. La audacia y el deseo de } \\
\text { vencer son temas comunes. }\end{array}$ & & \\
\hline $\mathrm{D}$ & $\begin{array}{l}\text { Lo que une a la organización es el conjunto de reglas } \\
\text { y políticas formales. Es importante mantener una } \\
\text { organización que funcione sin contratiempos. }\end{array}$ & & \\
\hline & TOTAL & & \\
\hline & Énfasis Estratégico & Ahora & Preferencia \\
\hline $\mathrm{A}$ & $\begin{array}{l}\text { La organización hace énfasis en el desarrollo humano. } \\
\text { Persisten altos niveles de confianza, franqueza y } \\
\text { participación. }\end{array}$ & & \\
\hline $\mathrm{B}$ & $\begin{array}{l}\text { La organización hace énfasis en adquirir nuevos } \\
\text { recursos y crear nuevos retos. Se valora el intentar } \\
\text { cosas nuevas y explorar posibilidades futuras como } \\
\text { oportunidades. }\end{array}$ & & \\
\hline $\mathrm{C}$ & $\begin{array}{l}\text { La organización hace énfasis en promover acciones } \\
\text { competitivas y consecución inmediata de resultados. }\end{array}$ & & \\
\hline $\mathrm{D}$ & $\begin{array}{l}\text { La organización hace énfasis en la permanencia y la } \\
\text { estabilidad. Son importantes la eficiencia, el control y } \\
\text { la fluidez de las operaciones. }\end{array}$ & & \\
\hline \multicolumn{2}{|r|}{ 6. Criterios de Éxito } & Ahora & Preferencia \\
\hline $\mathrm{A}$ & $\begin{array}{l}\text { La organización define el éxito sobre la base del } \\
\text { desarrollo del recurso humano, trabajo en equipo, } \\
\text { compromiso de sus empleados e interés por las } \\
\text { personas. }\end{array}$ & & \\
\hline $\mathrm{B}$ & $\begin{array}{l}\text { La organización define el éxito sobre la base de contar } \\
\text { con el mejor producto. Es líder en el producto y en su } \\
\text { innovación. }\end{array}$ & & 3 \\
\hline $\mathrm{C}$ & $\begin{array}{l}\text { La organización define el éxito sobre la base de vencer } \\
\text { y mantenerse a distancia de la competencia. El } \\
\text { liderazgo competitivo es clave. }\end{array}$ & & \\
\hline $\mathrm{D}$ & $\begin{array}{l}\text { La organización define el éxito sobre la base de la } \\
\text { eficiencia. La entrega confiable y los cronogramas sin } \\
\text { contratiempos son elementos críticos. }\end{array}$ & & \\
\hline & TOTAL & & \\
\hline
\end{tabular}

Al terminar el cuestionario enviarlo junto con el consentimiento informado a jimena.cerpa@gmail.com

¡Muchas gracias! 


\section{ANEXO 4: CRITERIO DE JUECES}

\section{CARTA DE SOLICITUD PARA JUICIO DE EXPERTOS}

Estimado (a):

Mi nombre es Jimena Cerpa Noya y soy bachiller en Psicología de la Universidad de Lima, Perú. Actualmente estoy buscando obtener mi licenciatura a través de un proyecto de tesis que tiene como objetivo de estudio adaptar y determinar las características psicométricas del Organizational Culture Assesment Instrument (OCAI) en la población limeña.

Es por ello que solicito su ayuda para la evaluación como experto en diseño de metodologías de evaluación. La versión original del OCAI fue realizado por Kim Cameron y Robert Quinn (1999). El instrumento tiene como objetivo evaluar la cultura organizacional de una organización en la actualidad y cuál sería la cultura organizacional de preferencia de dicha organización.

El instrumento cuenta con 24 ítems distribuidos en 6 dimensiones:

1. Características dominantes: Las características dominantes de la organización o cómo es en general.

2. Liderazgo Organizacional: El estilo de liderazgo o el enfoque que adquiere la organización.

3. Gestión de empleados: La gestión de los empleados o el estilo que caracteriza cómo los empleados son tratados y como es el ambiente laboral.

4. Cohesión Organizacional: El mecanismo de unión que mantiene a la organización adherida.

5. Énfasis Estratégico: Los ejes estratégicos que definen las áreas de énfasis que manejan la estrategia de la organización.

6. Criterios de Éxito: Los criterios de éxito que determinan cómo el triunfo es definido y que es lo que se recompensa y que es lo que se celebra.

Su tarea consiste en revisar y calificar los ítems agrupados de acuerdo a las dimensiones mencionadas anteriormente, de acuerdo a los siguientes criterios: 
- Congruencia: Si el ítem se relaciona con el indicador, dimensión y variable que se pretende medir o describir.

- Claridad: La redacción del ítem facilita su comprensión.

- Relevancia: El ítem es esencial o relevante para la investigación.

Para ello le anexo: 1) El instrumento que debe ser evaluado. 2) Una plantilla para recoger sus valoraciones sobre los ítems.

Por favor identifique el ítem o pregunta y conteste marcando con un aspa en la casilla que usted considere pertinente. Además puede hacerme llegar algún otro comentario en la columna adicional de observaciones si lo considera necesario.

Agradeciendo de antemano su valiosa colaboración, me despido de usted,

Atentamente,

Jimena Cerpa Noya

DNI 46855864 


\section{ANEXO 5}

\section{Formato para validar instrumento con juicio de expertos}

Queremos conocer cómo percibes la cultura organizacional en tu organización actualmente y cuál sería tu cultura de preferencia. Por favor, valora la medida en que los siguientes enunciados la identifican y contesta en el casillero correspondiente.

\begin{tabular}{|c|c|c|c|c|c|c|c|c|c|}
\hline \multirow{3}{*}{$\mathbf{N}$} & \multirow{3}{*}{ Dimensiones } & & \multicolumn{7}{|c|}{ ASPECTOS A EVALUAR } \\
\hline & & Ítem & \multicolumn{2}{|c|}{$\begin{array}{l}\text { Congruencia } \\
\text { Si el ítem se } \\
\text { relaciona con el } \\
\text { indicador, } \\
\text { dimensión y } \\
\text { variable que se } \\
\text { pretende medir o } \\
\text { describir } \\
\end{array}$} & \multicolumn{2}{|c|}{$\begin{array}{l}\text { Claridad } \\
\text { La redacción del } \\
\text { ítem facilita su } \\
\text { comprensión }\end{array}$} & \multicolumn{2}{|c|}{$\begin{array}{c}\text { Relevancia } \\
\text { El ítem es } \\
\text { esencial o } \\
\text { relevante para la } \\
\text { investigación }\end{array}$} & \multirow[t]{2}{*}{ Observaciones } \\
\hline & & & Sí & No & Sí & No & Sí & No & \\
\hline 1 & Características & $\begin{array}{l}\text { La organización es un lugar muy } \\
\text { personal. Es como una familia. } \\
\text { Las personas parecen compartir } \\
\text { mucho de sí mismas. }\end{array}$ & & & & & & & \\
\hline 2 & $\begin{array}{l}\text { Dominantes } \\
\text { Las } \\
\text { características }\end{array}$ & $\begin{array}{l}\text { La organización es un lugar muy } \\
\text { dinámico y empresarial. Las } \\
\text { personas están dispuestas a hacer } \\
\text { valer sus ideas y tomar riesgos. }\end{array}$ & & & & & $f^{\prime}$ & & \\
\hline 3 & $\begin{array}{l}\text { dominantes de la } \\
\text { organización o } \\
\text { cómo es en } \\
\text { general. }\end{array}$ & $\begin{array}{l}\text { La organización está muy } \\
\text { orientada hacia resultados. Una } \\
\text { preocupación principal es } \\
\text { realizar a cabalidad el trabajo. } \\
\text { Las personas son muy } \\
\text { competitivas y orientadas hacia } \\
\text { completar sus tareas. }\end{array}$ & & & & & the & & \\
\hline
\end{tabular}




\begin{tabular}{|c|c|c|c|c|c|c|c|c|c|}
\hline 4 & & $\begin{array}{l}\text { La organización es un lugar muy } \\
\text { controlado y estructurado. Por lo } \\
\text { general los procedimientos } \\
\text { formales gobiernan lo que la } \\
\text { gente hace. }\end{array}$ & & & & & & & \\
\hline 5 & 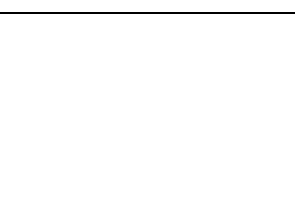 & $\begin{array}{l}\text { El liderazgo en la organización es } \\
\text { por lo general considerado como } \\
\text { ejemplo de buena conducción, } \\
\text { asistencia, o entrenamiento. }\end{array}$ & & & & & & & \\
\hline 6 & $\begin{array}{c}\text { Liderazgo } \\
\text { Organizacional }\end{array}$ & $\begin{array}{l}\text { El liderazgo en la organización es } \\
\text { por lo general considerado como } \\
\text { ejemplo de mentalidad } \\
\text { empresarial, innovación o } \\
\text { adopción de riesgos. }\end{array}$ & & & & & & & \\
\hline 7 & $\begin{array}{l}\text { El estilo de } \\
\text { liderazgo o el } \\
\text { enfoque que } \\
\text { adquiere la } \\
\text { organización. }\end{array}$ & $\begin{array}{l}\text { El liderazgo en la organización es } \\
\text { por lo general considerado como } \\
\text { ejemplo de un enfoque agresivo, } \\
\text { orientado hacia los resultados y } \\
\text { que deja de lado lo que no es } \\
\text { importante. }\end{array}$ & & & & & & & \\
\hline 8 & & $\begin{array}{l}\text { El liderazgo en la organización es } \\
\text { por lo general considerado como } \\
\text { ejemplo de eficiencia en la } \\
\text { coordinación, la organización y el } \\
\text { desarrollo sin contratiempos. }\end{array}$ & & & & & & & \\
\hline 9 & $\begin{array}{l}\text { Gerencia de } \\
\text { Empleados }\end{array}$ & $\begin{array}{l}\text { El estilo gerencial de la } \\
\text { organización está caracterizado } \\
\text { por trabajo en equipo, consenso y } \\
\text { participación. }\end{array}$ & & & & & & & \\
\hline
\end{tabular}




\begin{tabular}{|c|c|c|c|c|c|c|c|c|}
\hline 10 & $\begin{array}{l}\text { La gestión de los } \\
\text { empleados o el } \\
\text { estilo que } \\
\text { caracteriza cómo }\end{array}$ & $\begin{array}{l}\text { El estilo gerencial de la } \\
\text { organización está caracterizado } \\
\text { por adopción individual de riesgos, } \\
\text { innovación, libertad y excelencia. }\end{array}$ & & & & & & \\
\hline 11 & $\begin{array}{l}\text { los empleados } \\
\text { son tratados y } \\
\text { como es el } \\
\text { ambiente laboral. }\end{array}$ & $\begin{array}{l}\text { El estilo gerencial de la } \\
\text { organización está caracterizado } \\
\text { por alta competitividad, altas } \\
\text { demandas y logros. }\end{array}$ & & & & & & \\
\hline 12 & & $\begin{array}{l}\text { El estilo gerencial de la } \\
\text { organización está caracterizado } \\
\text { por seguridad de empleo, } \\
\text { conformidad, accionar predecible } \\
\text { y estabilidad en las relaciones. }\end{array}$ & & & & & & \\
\hline 13 & & $\begin{array}{l}\text { Lo que une a la organización es la } \\
\text { lealtad y la confianza mutua. El } \\
\text { compromiso con esta organización } \\
\text { es una prioridad. }\end{array}$ & & & & & & \\
\hline 14 & $\begin{array}{c}\text { Cohesión } \\
\text { Organizacional }\end{array}$ & $\begin{array}{l}\text { Lo que une a la organización es el } \\
\text { compromiso con la innovación y el } \\
\text { desarrollo. Se hace énfasis en estar } \\
\text { en la vanguardia. }\end{array}$ & & & & & & \\
\hline 15 & $\begin{array}{l}\text { El mecanismo de } \\
\text { unión que } \\
\text { mantiene a la } \\
\text { organización } \\
\text { adherida. }\end{array}$ & $\begin{array}{l}\text { Lo que une a la organización es el } \\
\text { énfasis en los logros y la } \\
\text { realización de objetivos. La } \\
\text { agresividad y el deseo de vencer } \\
\text { son temas comunes. }\end{array}$ & & & & & & \\
\hline 16 & & $\begin{array}{l}\text { Lo que une a la organización es el } \\
\text { conjunto de reglas y políticas } \\
\text { formales. Es importante mantener } \\
\text { una organización que funcione sin } \\
\text { contratiempos. }\end{array}$ & 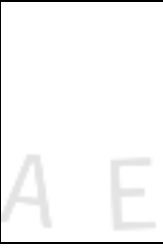 & & & & & \\
\hline
\end{tabular}




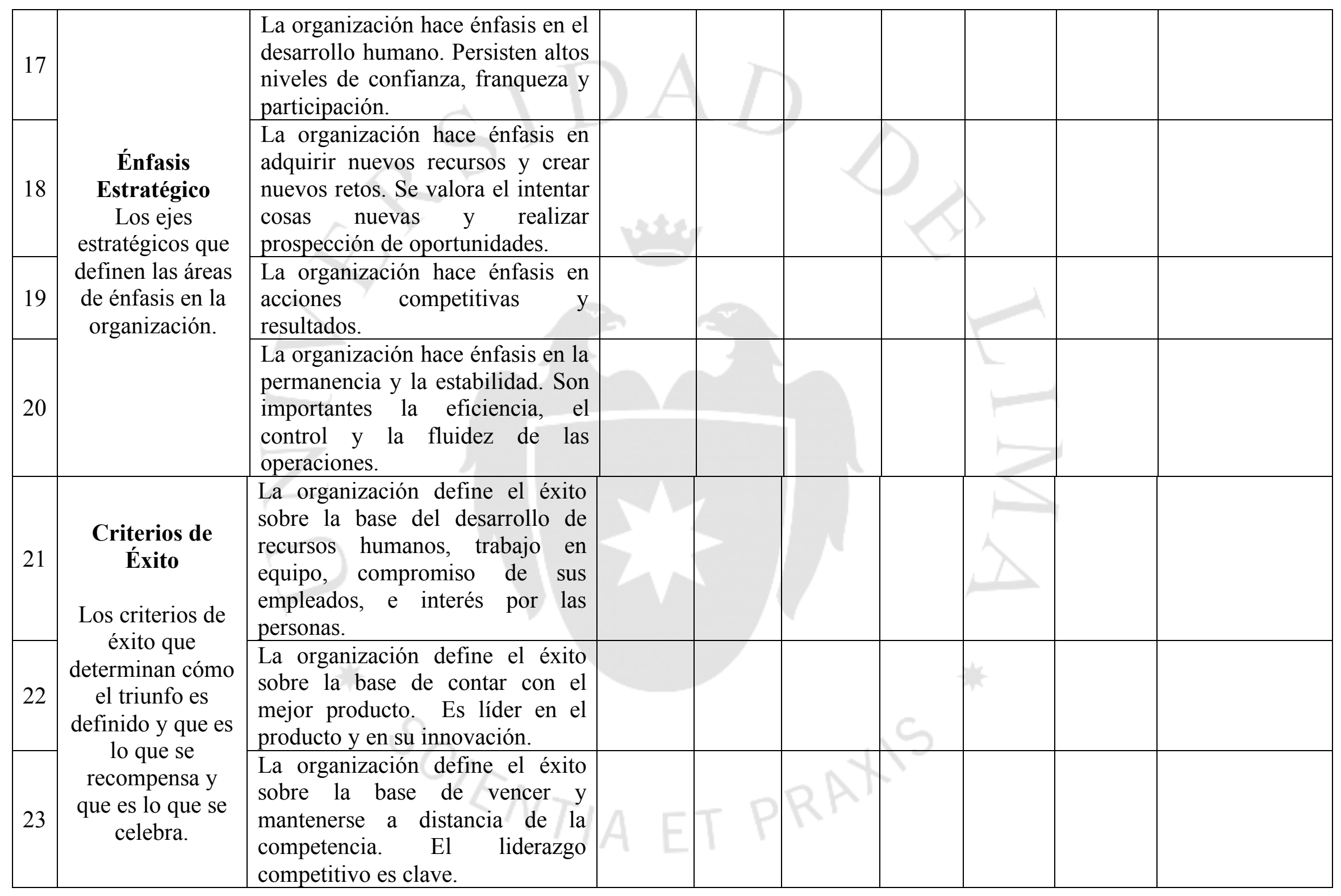




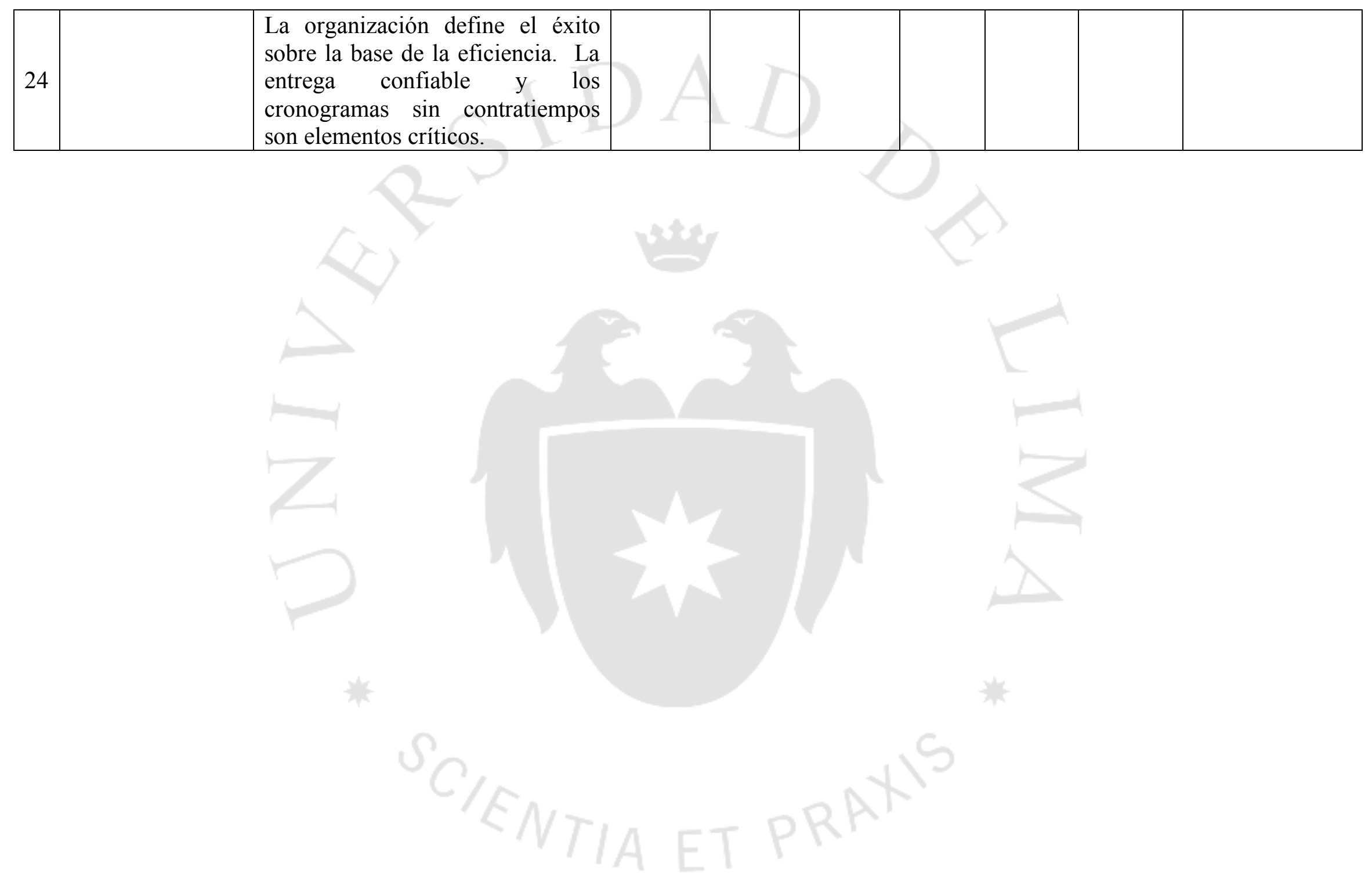




\section{ANEXO 6: Consentimiento informado}

El propósito de esta ficha de consentimiento es proveer al participante en esta investigación una clara explicación de la naturaleza de la misma, así como de su rol en ella como participante.

La presente investigación es conducida por Jimena Cerpa Noya de la Universidad de Lima. La meta de este estudio es analizar las propiedades psicométricas del OCAI (Organizational Culture Assesment Instrument).

Si usted accede a participar en este estudio, se le pedirá responder preguntas de un cuestionario. Esto tomará aproximadamente 20 minutos de su tiempo.

La participación en este estudio es estrictamente voluntaria. La información que se recoja será confidencial y no se usará para ningún otro propósito fuera de los de esta investigación. Sus respuestas al cuestionario serán codificadas usando un número de identificación.

Si tiene alguna duda sobre este proyecto, puede hacer preguntas en cualquier momento durante su participación en él. Igualmente, puede retirarse del mismo en cualquier momento sin que eso lo perjudique en ninguna forma. De tener preguntas sobre mi participación en este estudio, puedo contactar a Jimena Cerpa Noya al teléfono 985325304.

Desde ya le agradezco su participación. 